\title{
Multi-Object Auctions with Resale: Theory and Experiment
}

\author{
Emel Filiz-Ozbay, Kristian Lopez-Vargas and Erkut Y. Ozbay ${ }^{1}$
}

September 2014

\begin{abstract}
We study multi-object auctions in the presence of post-auction trade opportunities among bidders who have either single- or multi-object demand. We focus on two formats: Vickrey auctions where package bidding is possible and simultaneous second-price auctions. We show that, under complementarities, the Vickrey format has an equilibrium where the objects are allocated efficiently at the auction stage whether resale markets are present or not. The simultaneous second-price, on the other hand, leads to inefficiency with or without resale possibility. Our experimental findings show that the possibility of resale in second-price auctions decreases the efficiency rate at the auction stage compared to the no resale case. However, after resale, the efficiency rate in second-price is as high as that of Vickrey auction without resale outcomes in the experiment. Preventing resale neither benefits nor hurts auction revenues in a second-price format. (JEL D44, C72, C91)
\end{abstract}

Keywords: Multi-object Auctions, Vickrey, Second-Price, Package, Resale

\footnotetext{
1 Department of Economics, University of Maryland. Correspondence to: filizozbay@econ.umd.edu, lopez-vargas@econ.umd.edu, and ozbay@econ.umd.edu. We thank Lawrence Ausubel, Peter Cramton, Jacob Goeree, Isa Hafalir, Dan Levin, Thayer Morrill, Dan Vincent and seminar participants at Duke University, Johns Hopkins University, North Carolina State University and Sabanci University for fruitful discussions. Emel Filiz-Ozbay and Erkut Y. Ozbay thank NSF SES-0924773 for research support.
} 


\section{Introduction}

The large scale of privatization of assets, such as spectrum licenses, and gas and electricity supply, attracts attention to multi-object auctions (see e.g. Krishna and Perry (2000); Ausubel (2004)). Unlike the auctioning of non-government owned assets, the efficiency of the allocation, rather than revenue maximization, is the main objective of these auctions (see McMillan (1994); Ausubel and Cramton (1999); Cramton (2002)). This objective may be achieved at the auction stage or by allowing post auction trade among bidders.

As a means of allocating objects efficiently, Vickrey auctions are often considered. The attractiveness of a Vickrey auction is that it extracts the true value of the bidders via simple strategies that are independent of the underlying distribution of values (see Ausubel and Milgrom (2006)). On the other hand, conducting a Vickrey auction, explaining its pricing rule and its transparency to the bidders, can be quite complex, especially when there are large packages of objects and many bidders. Due to these complexities, most spectrum auctions in the US do not allow for package bidding and, in rare cases, such as a $700 \mathrm{MHz}$ auction, allow bids on only a limited number of packages (Cramton (2002)). Running simultaneous second-price auctions may be more practical but may lead to inefficient allocations when complementarities exist (see de Vries and Vohra (2003); Cramton et al. (2006)). In that case, bidders are naturally interested in resale at the conclusion of the auction.

Post auction trades among bidders are observed in various settings, such as auctions of antiques, real estate, art, emission allowances, or spectrum licenses. In government auctions, where one would expect the government to be able to forbid resale, it is hard to prevent companies from merging (as was the case after the UK spectrum auctions in 2000 and 2003) $)^{2}$. Therefore, it is important to understand both theoretically and empirically how auction outcomes are affected by the existence of resale markets.

\footnotetext{
${ }^{2}$ Hutchison, a telecommunications company, bought TIW, a Canadian firm which won the most valuable license, just after the spectrum auctions in 2000. Pacific Century Cyberworks, a large Hong Kong company, took over Red Spectrum and Public Hub, two small firms, less than a year after the UK spectrum auctions in 2003.
} 
Various studies have shown that, typically, auction behavior is affected by the possibility of resale and therefore the efficiency and revenue of the auction may change depending on the existence of resale markets (see e.g. Haile (1999, 2000, 2001, 2003), Gupta and Lebrun (1999), Hafalir and Krishna (2008), Zheng (2002), Garratt and Tröger (2006)).

When multi-objects are auctioned, bidders' demands may differ depending on how large or small they are. For example, in FCC auctions, some bidders are smaller than others because of geographical restrictions or financial constraints, or because they have different uses for the objects. Therefore, they prefer to bid on only a small number of licenses. Moreover, in spectrum auctions (as well as in many other settings), large companies might value multiple licenses to serve large geographical locations more than the sum of the values of each license because the marginal cost of serving a larger area can be lower. In our model, we consider one large bidder (the global bidder) and $N$ small bidders (the local bidders). There are $N$ units to be sold. The global bidder is interested in all units, and each local bidder is interested in a single unit (see Krishna and Rosenthal (1996), and Chernomaz and Levin (2012) for similar settings ${ }^{3}$ ). The valuations of the bidders are independent and private. This setup resembles the situation of telecommunications firms interested in radio-frequencies in different areas, which might have independent valuations due to the varying demands in different geographical regions.

We study both Vickrey auctions where package bidding is allowed and simultaneous second-price auctions where an auction is conducted for each unit. We consider the case where resale among bidders is allowed and the case where it is not. The resale markets, when they are allowed, are designed so that the winners of the auction can make a take-it-or-leave-it offer to the unsuccessful bidders as in Hafalir and Krishna (2008).

\footnotetext{
${ }^{3}$ Krishna and Rosenthal (1996) develop this model in order to study the FCC auctions of licenses for the radio-frequency spectrum. Chernomaz and Levin (2012) study theoretically and experimentally first-price auctions in this setting. Neither of these models allows for post-auction resale.
} 
We show that the Vickrey auction with package bidding has an equilibrium that allocates objects efficiently at the auction stage with or without resale possibility. Particularly, truthful value bidding is equilibrium when resale is allowed. Hence, resale trade will not occur after a Vickrey auction in that equilibrium. On the other hand, simultaneous second-price auctions do not allocate the objects efficiently at the auction stage when resale is possible or prohibited in any equilibrium. Moreover, in any equilibrium of these auctions, full efficiency cannot be achieved by resale.

Based on these theoretical findings, it is important to investigate experimentally the tradeoff between running a complex but efficient Vickrey auction, and a simple but inefficient simultaneous second-price auction. First, our Vickrey auction experiments with or without resale do not achieve efficiency. The complexity of this pricing rule makes it hard for the subjects to discover that simple efficient equilibrium. Additionally, our experiments compare simultaneous second-price auctions when resale is allowed and not allowed in terms of efficiency. We show that the presence of resale markets diminishes the efficiency rates at the auction stage of the second-price format compared to the no-resale case. However, in this format, after resale, efficiency rates improve to the level of the outcome of our Vickrey auctions without resale experiments.

Although revenue may not be the main concern of government auctions, resale activity is typically considered a loss of the seller from the gains of trade. Contrary to this intuition, our experiments show that the resale possibility does not affect seller's revenue significantly in second-price auctions.

The existing models of auctions with resale in the literature mainly consider single object problems. The literature on auctions with resale provides six main reasons for resale: (i) New information regarding the values of objects arrives after the auctions (see Haile (1999, 2000, 2001, 2003) and Gupta and Lebrun (1999)), (ii) new buyers arrive after the auction is over (Haile (1999)), (iii) asymmetry in the auction may lead to inefficient allocation (Zheng (2002); Hafalir and Krishna (2008)), (iv) presence of speculators in the auction (Garratt and Tröger (2006); Pagnozzi (2007, 2009, 2010)), (v) coordination on collusive outcome (Garratt, Tröger, and Zheng (2009)), and (vi) 
misperception of resale markets (Georganas (2011)). Our setup is closest to the third type because a multi-object auction setting with complementarities provides a natural asymmetry in terms of demand of bidders and therefore may lead to inefficient allocation under different formats.

The experimental literature on auctions with resale is limited, probably because the theoretical developments on this topic are relatively recent. Lange, List and Price (2011) experimentally study symmetric first-price auctions where bidders' valuations are initially noisy and there is room for resale. Georganas and Kagel (2011) test Hafalir and Krishna (2008). Georganas (2011) experimentally studies symmetric English auctions with resale and shows deviations from equilibrium that he interprets as misperception of resale. The only other paper, to the best of our knowledge, studying a multi-object setting with resale possibility is Pagnozzi and Jabs-Saral (2013). Their paper complements ours as they analyze different bargaining mechanisms at resale stage following a uniform price auction without complementarities.

The rest of the paper is organized as follows. Section 2 presents our theoretical model and states the theoretical results that motivate the experiments. Section 3 summarizes the experimental design and findings. Section 4 concludes. The proofs of the statements presented in the theoretical section and the instructions used in the experiments can be found in the online Appendix.

\section{Model}

Our setup is similar to the model introduced by Krishna and Rosenthal (1996) (see also Chernomaz and Levin (2012), and Goeree and Lien (2012)). There are $N>1$ markets, each containing one object for sale. Markets are indexed by $i \in\{1, \ldots, N\}$. There are $N$ local bidders and local $i \in\{1, \ldots, N\}$ is denoted by $l_{i}$. Local $i$ is present only in market $i$. There is a global bidder (denoted by $g$ ), who is present in all markets. ${ }^{4}$ All bidders are risk-neutral.

\footnotetext{
${ }^{4}$ For example, a local broadcaster is interested only in the license to serve its region, while a national broadcaster is present in markets for all regions. This is in line with the motivation of Krishna and Rosenthal (1996). Nevertheless, the local bidders may want to bid in other markets
} 
Before the auction, each bidder privately observes a signal. Each bidder's signal is drawn from a commonly known distribution function $F$ defined on a support $[0, \bar{s}]$ with $\bar{s}>0$. Signals are independently and identically distributed.

The value of the objects for the seller is zero. For each local bidder, her signal is her private value for the object that she is interested in. Also, for a given signal of the global bidder, any two packages of the same size are valued the same. ${ }^{5}$ Formally, $v^{n}(s)$ is the value of obtaining $n \geq 1$ objects when the signal of the global bidder is $s$. There are complementarities for the global bidder: $v^{n}(s)>v^{n-k}(s)+v^{k}(s)$ for any $0<k<n \leq N$ and $s>0$. For each $n, v^{n}(s)$ is strictly increasing and differentiable in $s$, and the derivative is strictly increasing in $n$, i.e. $v^{n^{\prime}}(s)>v^{n-1^{\prime}}(s)$ for any $s$. As a normalization, $v^{1}(s)=\mathrm{s}$. Also, $v^{n}(0)=0$ for any $n$. For example, when $N=2$, $v^{2}(s)=2 s+\alpha$ with $\alpha>0$ (as in Krishna and Rosenthal (1996)) and $v^{2}(s)=2 \beta s$ with $\beta>1$ (as in Chernomaz and Levin (2012)) satisfy all the aforementioned assumptions.

The objects are first auctioned to the bidders and then the bidders may trade the objects with each other at a post-auction resale stage when it is allowed (we will study auctions with and without resale possibility).

\section{Auction Stage}

We study two types of auction formats:

- Simultaneous Second-Price Auctions: $N$ simultaneous auctions are run, one for each market. In market $i$, local $i$ and global submit their bids. The highest bidder receives object $i$ and pays the losing bid (the second highest bid) of that market.

when there is resale possibility. Allowing this kind of speculative bidding may lead to having many buyers at the resale stage and hence complicate the post auction trading. Additionally, in reality, some restrictions, such as geographical or legal, may prevent such speculative bidding. Therefore, we rule out this possibility.

${ }^{5}$ Given the auction formats that we analyze, this assumption is made to simplify the notation. 
- Vickrey Auction ${ }^{6}: N$ objects are sold in one auction. Local $i$ submits a bid for object $i$; the global submits bids for each possible package of objects. The objects are allocated to those bidders who have the highest total bids for all the auctioned objects. Each winner pays a price that is equivalent to the externality she exerts on other bidders.

Independent of the auction format, all bids are disclosed after the auctions. ${ }^{7}$

\section{Resale Stage}

After the auction stage is completed, each winner may offer a price at which to sell the object to the losing bidder of the corresponding market (as in, e.g. Hafalir and Krishna (2008)). These take-it-or-leave-it offers cannot be negotiated. If an offer is accepted, the trade takes place at the offered price. If it is rejected, the winner of the auction keeps the object. The timing of the offers is as follows ${ }^{8}$ : If the global wins all the objects, she makes $N$ simultaneous offers to the losing locals. If the locals win $n$ objects and the global wins $N-n$ objects, first the $n$ winning locals make offers to the global, sequentially. The order of the locals' offers is randomly determined, and every local observes each offer as it occurs. After the global sees $n$ offers that are made to her, and before deciding whether to accept them, the global makes simultaneous offers to $N-n$ losing locals. After all the offers are made, first the losing locals decide whether to accept

\footnotetext{
${ }^{6}$ This is equivalent to the second-price auction when a single object is auctioned. It is considered the appropriate generalization of the second-price auction for multi-object settings (see e.g. Krishna 2002).

${ }^{7}$ In these auctions the losing bids are, naturally, disclosed to the winners because the losing bids determine the prices that the winner pays. When the global wins all the objects or none of the objects, announcing the winning bids reveals redundant information since the winner sets the price in the resale stage (see the description of the resale stage). Although observing all winning bids may potentially affect a local's offer in the resale stage when global wins in other markets, in Table 8 we see that this information is not a significant variable affecting the resale price of the local.

${ }^{8}$ This sequential take-it-or-leave-it offer protocol generalizes to the standard bilateral case in the sense that under complete information the trade is efficient and the unique equilibrium price gives the full surplus to the offering party. This unique equilibrium property wouldn't hold with some other generalizations such as simultaneous offers.
} 
or reject, then the global observes these decisions and decides whether to accept or reject the offers that are made to her. ${ }^{9}$

Throughout the paper, we study Perfect Bayesian Nash Equilibrium. It is common knowledge among bidders whether or not a resale stage will follow the auction.

\subsection{Simultaneous Second-Price Auctions with and without Resale}

When there are no complementarities between objects and resale is not allowed, it is well known that sincere signal bidding is an efficient equilibrium in weakly dominant strategies. Our first observation states that when complementarities exist, there is no equilibrium in which goods are allocated efficiently at the auction stage. This is true regardless of whether resale is allowed or not.

The equilibrium bid strategies are denoted by $\left\{b_{i}\left(s_{i}\right), b_{g_{i}}\left(s_{g}\right)\right\}_{i \in\{1, \ldots, N\}}$ where $b_{i}\left(s_{i}\right)$ is the bid of local $i$ with signal $s_{i}$, and $b_{g_{i}}\left(s_{g}\right)$ is the bid of global in market $i$ when she has signal $s_{g}$.

Proposition 1. The simultaneous second-price auctions do not have any equilibrium where the auction stage allocates objects efficiently. This is true whether resale is allowed or not.

The intuition behind this proposition is as follows. Without complementarities, efficient allocation depends only on the ranking of values within each market. Consequently, any equilibrium that is monotone and symmetric will be efficient (in particular, sincere bidding). Under complementarities, however, the efficiency of the

\footnotetext{
${ }^{9}$ Although we commit to this resale protocol in the theoretical model and the experimental design, our results on auctions with resale, Propositions 2 and 3, hold if instead losing bidders make the resale offers or the proposer of the resale offer is randomly determined at the resale stage. Moreover, even if the global bidder is allowed to make conditional offers in the resale stage, the theoretical results still hold. Although it is experimentally possible that global bidder who wins both objects may end up selling only one object at a low price while expecting to sell both at a profitable level, such an exposure problem is observed very rarely (only $1.57 \%$ in SPR and $1.62 \%$ in VR). Nevertheless, it is important to note that such global bidders might have set a price anticipating this exposure problem in the resale stage. One may investigate whether the bidders take into account the potential exposure problem in the resale stage by running a treatment by allowing for conditional offers.
} 
whole game is entangled. Although the bidding strategies must depend only on the bidders' own signals, the efficient allocation in market $i$ might depend on the realization of signals in other markets.

This result indicates that the auction stage is inefficient, but it is not clear whether or not allowing for resale will lead to efficient allocation eventually. Next, we show that any equilibrium of the SP auctions with resale will be inefficient in the final outcome (after the resale stage).

Proposition 2. The simultaneous second-price auction with resale has no efficient equilibria.

The idea of the proof of Proposition 2 is that if a small downward deviation by a bidder who loses inefficiently for some realization of signals was not beneficial, then her upward deviations would be beneficial. This means that the bid strategy of a bidder cannot be strictly monotone for signal ranges where she may lose inefficiently. Hence, whenever a bidder loses the auction inefficiently, the winner could not infer the loser's value from her bid. Such a "ratchet effect" as studied by Laffont and Tirole (1988) has been applied to auctions by Lebrun (2010) and Xu, Levin and Ye (2012). The techniques used in the literature are not applicable to our setting because we have multiple auctions at the same time. Our proof uses a vector calculus technique extensively used in physics. This technique is novel in auction theory and might be found useful in other applications.

Proposition 2 implies that this game does not have a separating equilibrium. As can be seen from the proof, this means that the equilibrium bid functions should have some pooling portion. Moreover, this result is robust to the resale protocols where losing bidders make the resale offer, the proposer is randomly determined, the global makes the first offers when she wins only some of the objects, or the global is allowed to make contingent resale offers. The exact nature of the resale protocol is irrelevant for this result because it is a proof by contradiction where we assume that the auction bids reveal the signals of the bidders whenever the auction outcome is inefficient. This implies that the bidders know the nature of the efficient trade and which prices are acceptable or not at 
the resale stage of such equilibrium. Those different resale protocols affect the resale price but not the post trade allocation of objects (because in the proof by contradiction the final allocation is always assumed to be the efficient one). Since the proof does not particularly rely on the resale price, the arguments still hold under these alternative protocols.

Remark 1: The simultaneous second-price auction with resale has a pooling equilibrium where locals bid zero and the global bids $v^{N}(\bar{s})$ in each market for any realization of signals. In this equilibrium, the global always wins the auctions, and no information regarding the signals will be revealed in the resale stage. The global offers the price vector that maximizes her expected payoff given her signal.

It is also a pooling equilibrium for the global to bid zero in each market, and the locals bid $v^{N}(\bar{s})$ independent of their signals. The resale stage prices are set optimally. In both of these equilibria, the after resale allocation will be inefficient with positive probability.

The two equilibria characterized in Remark 1 are completely uninformative at the auction stage, and they are "collusive" in the sense that the bidders should somehow coordinate on who bids zero. Since the theory predicts impossibility of a separating equilibrium or any other equilibrium with a stronger solution concept (such as dominant strategy), coordination on one of the pooling or partially pooling equilibria will be unrealistic to expect from the subjects in our experiments. Nevertheless, the theory predicts inefficiency, and experiments can help us understand the severity of this inefficiency.

\subsection{Vickrey Auction with and without Resale}

In the auction stage, a single auction is run to sell all the objects. Each bidder submits bids for all possible packages of the objects that she is interested in. In our setup, this means that each local submits a bid for object $i$ and the global bidder submits bids for each package. The auction allocates the objects to the bidders who have the highest combined bids for all objects. Each winner pays a price that is equivalent to the 
externality she exerts on other competing bidders (Vickrey (1961)). This means that each winner pays the difference between what the highest total bid would have been if she did not participate in the auction (and the others bid the same) and what the highest total bid excluding her bid is in the current situation.

If resale is not allowed after the auction, it is known that a Vickrey auction has an efficient equilibrium (Vickrey (1961)). In this equilibrium, value bidding is a weakly dominant strategy. ${ }^{10}$ In Proposition 3, we show that when there is resale possibility, a Vickrey auction still has an efficient equilibrium. Although bidding true valuation for each package remains an equilibrium strategy for the auction stage, it is no longer a weakly dominant one.

Proposition 3. The Vickrey auction with resale has an equilibrium that allocates the objects efficiently in the auction stage.

The proof of Proposition 3 constructs this efficient equilibrium where local $i$ bids $b_{i}^{*}\left(s_{i}\right)=s_{i}$, and the global bids $b_{g_{I}}^{*}\left(s_{g}\right)=v^{|I|}\left(s_{g}\right)$ for a package $I \subseteq\{1, \ldots, N\}$. Hence, the auction outcome is efficient, and no resale will occur. It is important to note that this result is robust to aforementioned alternative resale protocols.

\section{Experiment}

In the previous section, we saw that a Vickrey auction has an efficient equilibrium with and without resale. On the other hand, simultaneous second-price auctions may allocate the objects inefficiently at the auction stage whether there is a resale possibility or not. Furthermore, the existence of resale markets does not guarantee the efficiency of the final outcome. Our experiment is designed to study the following: (1) Comparisons of the efficiency rates in SP and Vickrey auctions with and without resale; (2) Sources of

\footnotetext{
${ }^{10}$ A Vickrey auction has other equilibria as shown in the literature (see Blume et al. (2009)). Similarly, when resale is allowed, there are implausible equilibria. As noted in Blume et al. (2009), in any equilibrium, except the value bidding equilibrium, the bidders need to coordinate on who bid zero similar to the equilibria of SPR discussed in Remark 1.
} 
efficiency losses when there are any; (3) Rankings of formats by the bidders and the seller.

\subsection{Design of the Experiment}

The experiments were run at the Experimental Economics Lab at the University of Maryland (EEL-UMD). All participants were undergraduate students. The experiment involved four treatments: simultaneous second-price auctions without resale (SPNR), simultaneous second-price auctions with resale (SPR), Vickrey auctions without resale (VNR), and Vickrey auctions with resale (VR). We conducted six sessions for each auction format. In each session, there were 15 subjects. No subject participated in more than one session. Therefore, we had 360 subjects. The random draws were balanced in the sense that we used the same sequence of random number "seed" signals for all auction formats, so that the random draws matched across treatments. A new set of random draws was used for each session in each format. Participants were seated in isolated booths. Each session lasted less than two hours. The instructions are provided in the Appendix. To test the subjects' understanding of the instructions, they had to answer a quiz before the experiment started. The auctions did not begin until each subject answered all of the questions correctly.

In each session, each subject participated in 30 auctions. Each subject was assigned a role, global or local, and the roles remained fixed throughout the session. Each auction had one global and two locals who were randomly matched. Two objects were auctioned. The global bidder was interested in both objects and each local was interested in a single object. More specifically, local 1 was interested in the object sold in Market 1 and local 2 was interested in the object in Market 2. Bidders were randomly re-matched after each auction. All bidding was anonymous. Bids were entered via computer. The experiment was programmed in z-Tree (Fischbacher (2007)). At the conclusion of each auction, the bidders learned the outcome of the auction (i.e. whether the global or a local won in each market and the submitted bids).

At the beginning of an auction, each bidder received a private signal from uniform distribution on $[0,100]$, independently. The signal of a local was her valuation for the 
object that she was interested in. The signal of a global was her valuation of the single object. A global's valuation for the package of two objects was $3 \times$ (her signal).

In treatments without resale possibility, the payoff of a subject in a round was the difference between the value of the object(s) that she received in the auction and the auction price. In treatments with resale possibility, a subject earned

Payoff $=($ Value of the object $(s)$ owned after resale $)+($ any amount received in a resale trade) - (any amount paid in auction or resale stage).

All the amounts in the experiment were in Experimental Currency Units (ECU). Subjects received $\$ 7$ as participation fee and \$3 initial endowment to cover any possible losses in the experiment. No subject lost all of the initial endowment. The final earnings of a subject were the sum of her payoffs in 20 randomly selected rounds in addition to the participation fee and the initial endowment. The payoffs in the experiment were converted to US dollars at the conversion rate of $50 \mathrm{ECU}=\$ 1$. Cash payments were made at the conclusion of the experiment. The average subject payment was $\$ 19.85$.

Simultaneous Second-Price Auctions without Resale (SPNR): Each local bidder submitted a bid only for the object in her market. The global bidder submitted bids for each object. Bids could be any integer number from $\{0,1,2, \ldots, 300\}$. The computer allocated each object to the bidder who submitted the highest bid for that object. A winner's payment was what the losing bidder bid for the object.

It is immediate to show that, when resale is not allowed, truthful value bidding is the local bidders' weakly dominant strategy. Only the global bidder has a non-trivial problem. Proposition 4 shows how the equilibrium can be constructed in this case for the parameters used in the experiment.

Proposition 4: In the simultaneous second-price auctions without resale when $N=2$, $v^{2}(s)=3 s$, and the signals are independently and uniformly distributed on $[0,100]$, truthful value bidding is the locals' weakly dominant strategy and global's equilibrium bidding strategy in market $i \in\{1,2\}$ is $b_{g_{i}}^{*}(s)=b_{g}^{*}(s)=\min \left\{\frac{100 s}{100-s}, 100\right\}$. 
Vickrey Auction (VNR): Each local bidder submitted a bid only for the object in her market. The global bidder submitted a bid for each object and a bid for the package containing both objects. Therefore, the global submitted three bids. Bids could be any integer number from $\{0,1, \ldots, 300\}$. The computer allocated the objects to the set of bidders who submitted the highest combined bids for the two objects. A local winner's payment was calculated by the following formula:

$$
\begin{aligned}
\text { Price }= & (\text { the highest total bid if that winner were NOT present }) \\
& -(\text { the other winner's bid in the current highest total bid })
\end{aligned}
$$

For each object she wins, the global pays the local bidder's bid in that market.

Simultaneous Second-Price Auctions and Vickrey Auctions with Resale (SPR and VR): The auction stages of SPR and VR were the same as SPNR and VNR, respectively. After the auction stage was over, the bidders learned all the bids in each market and the resale stage started. Non-negotiable resale offers were made by the winners of the auction stage. In the experiment, in order to decrease the number of decisions to be made, all the winners of the auction stage were asked to make resale offers. Note that a winner who did not want to sell could always ask for an unacceptable resale price. ${ }^{11}$ If a resale trade took place, then the object was transferred to the buyer, the buyer paid, and the seller received the resale price. The timing of the resale offers was as follows:

- If the global won in both markets, then she made simultaneous offers to the locals. Upon observing the resale offers, the locals simultaneously decided whether to accept or reject the corresponding offer.

- If the two locals won the auctions, then one randomly determined local made the first resale offer; after observing this, the other local made an offer. After observing both locals' offers, the global decided whether to buy any object(s) in the resale stage.

\footnotetext{
${ }^{11}$ Although subjects were not explicitly told what an unacceptable resale price was, the subjects made unacceptable offers when they did not want to sell. 300ECU was the highest unacceptable offer for our parameters and subjects offered that price a few times (We observed resale price of 300 in 48 and 32 out of 900 auctions in SPR and VR, respectively).
} 
- If local $i$ won the auction in market $i$, and the global won the auction in market $j$, then first local $i$ made a resale offer. After observing this, the global made a resale offer to local $j$. Then local $j$ decided whether to accept the global's offer. Upon observing this, the global bidder decided whether to accept the local $i$ 's offer. All the moves in the sequential resale game described above were observable by the players.

\subsection{Experimental Results}

We start our analysis by considering the efficiency of the allocation in each treatment. We use the efficiency measure of Kagel and Levin (2001). In this definition, the efficiency of an auction is measured as the ratio of the total surplus of the allocation to the highest possible surplus among all possible allocations, where total surplus is the sum of bidder profit and auctioneer revenue. Then, for each auction, the ratio is normalized by the average surplus of all possible allocations as follows:

$$
\text { Efficiency }=\frac{\text { the actual total surplus }- \text { average surplus }}{\text { the highest possible surplus }- \text { average surplus }}
$$

Table 1 presents the efficiency rates for each auction format for all periods as well as the first and second halves of the experiment. For the pairwise comparisons of the efficiencies we run Mann-Whitney rank tests. Based on all periods' data, at the auction stage, SPR achieves significantly lower efficiency rates than VNR and SPNR ( $z=-9.067$; $p=0.0000$ and $z=-6.990 ; p=0.0000$, respectively). However, after the resale stage, the efficiency rate of SPR is significantly higher than that of SPNR $(z=3.706 ; p=0.0002)$ and is not significantly different from that of VNR $(z=1.031 ; p=0.3024)$. Note that in SPR, VNR and SPNR, the efficiency rates improve in the second half of the experiments; nevertheless, these efficiency comparisons are preserved. The difference between the efficiencies of VNR and SPNR is significant in the overall data $(z=2.585 ; \mathrm{p}=0.0098)$. However, due to learning in SPNR, this difference becomes insignificant when we look at the last 15 periods $(\mathrm{z}=1.004 ; \mathrm{p}=0.3154)$. 
VR achieves lower efficiency rates than other formats. We believe this is due to the difficulty of understanding both the Vickrey pricing rule and the resale protocol. Note that the efficiency rate after resale of VR is lower than its auction stage efficiency, and this is due to inefficient resale activities in the first half of the experiment. However, there is a learning effect, i.e. the inefficient resale was corrected in the second half of the experiment. But still the efficiency rate after resale is not significantly different from the one in the auction stage $(z=0.481 ; p=0.6303)$. Due to the subjects' apparent difficulty understanding the VR format, the detailed analysis of VR for Periods 16-30 is presented in Appendix B. ${ }^{12}$

Table 1: Average Efficiency Rates

\begin{tabular}{|c|c|c|c|}
\hline Auction Format & Periods $1-15$ & Periods $16-30$ & All Periods \\
\hline Vickrey - No Resale & $\begin{array}{c}.769 \\
(.044)\end{array}$ & $\begin{array}{c}.788 \\
(.027)\end{array}$ & $\begin{array}{l}.779 \\
(.03)\end{array}$ \\
\hline \multicolumn{4}{|l|}{ Vickrey - Resale } \\
\hline Auction Stage & $\begin{array}{c}.771 \\
(.026)\end{array}$ & $\begin{array}{c}.701 \\
(.024)\end{array}$ & $\begin{array}{c}.736 \\
(.008)\end{array}$ \\
\hline Resale Stage & $\begin{array}{c}.616 \\
(.045)\end{array}$ & $\begin{array}{c}.715 \\
(.039)\end{array}$ & $\begin{array}{c}.666 \\
(.041)\end{array}$ \\
\hline SP - No Resale & $\begin{array}{c}.708 \\
(.024)\end{array}$ & $\begin{array}{c}.783 \\
(.014)\end{array}$ & $\begin{array}{c}.745 \\
(.012)\end{array}$ \\
\hline \multicolumn{4}{|l|}{ SP - Resale } \\
\hline Auction Stage & $\begin{array}{c}.56 \\
(.056)\end{array}$ & $\begin{array}{c}.57 \\
(.051)\end{array}$ & $\begin{array}{c}.565 \\
(.051)\end{array}$ \\
\hline Resale Stage & $\begin{array}{c}.796 \\
(.039)\end{array}$ & $\begin{array}{c}.827 \\
(.027)\end{array}$ & $\begin{array}{c}.811 \\
(.025)\end{array}$ \\
\hline
\end{tabular}

Session-clustered standard errors are in parentheses.

\footnotetext{
${ }^{12}$ Appendix B also includes all the analysis restricted to the second half of the experiment for all the formats. As can be seen, the main results of the paper are not affected qualitatively.
} 
Recall that the equilibrium of VNR is efficient. However, the efficiency rate in the experiment is significantly less than 1 ( $\mathrm{p}=0.0000$, one-sided $\mathrm{t}$-test). This lack of efficiency is actually not surprising in Vickrey auction experiments (see Kagel and Levin (2011) for a detailed survey). Particularly, overbidding in single-object Vickrey auctions (see e.g. Kagel and Levin (1993)) and underbidding or truthful value bidding in multiobject Vickrey auctions (see Chen and Takeuchi (2010)) have been reported. Although the demand of each bidder is symmetric in the corresponding literature, our results extend these findings such that local bidders who are interested in only a single object overbid, while global bidders who are interested in two objects bid truthfully or underbid. For the draws used in the experiment, the equilibrium efficiency rate of SPNR stated in Proposition 4 is 0.95 , but the efficiency rate in the experiment is significantly less $(p=0.0000$, one-sided t-test). For SPR, we calculate the expected efficiency rate for the pooling equilibrium characterized in Remark 1 by the following simulation exercise. We assume that locals bid zero and the global with any signal $s$ always wins the auctions and sets the rational resale price of $\frac{100(100+s)}{200-s}$ given that the auction stage is uninformative. Then, we calculate the expected efficiency rate based on five million signal draws by using the parameters of the experiment. Such a pooling equilibrium leads to an efficiency rate of 0.77 , which is significantly less than what we observed in the experiments $(p=$ 0.0061 , two-sided t-test). ${ }^{13}$

Next we investigate the sources of the inefficiencies. The first three columns of Tables 2-4 present the number of auctions where the efficient outcome allocates both objects to the locals (column 1), one object to a local and one object to the global (column 2), and both objects to the global (column 3). The rows of Tables 2-4 classify actual allocations based on the type of winning bidders: both locals receive an object in the experiment per treatment (row 1), one local and the global receive one object each

\footnotetext{
${ }^{13}$ Given the complementarities, the equilibrium where the global wins the auction all the time will lead to higher efficiency than the equilibrium where the locals win the auction since the resale stage takes place with no information regarding the signals in both cases.
} 
(row 2), and the global receives both objects (row 3 ). The $4^{\text {th }}, 5^{\text {th }}$, and $6^{\text {th }}$ columns show for each type of efficient allocation, how actual allocations distributed in percentage terms. For example, out of 900 VNR auctions, in 576 auctions the global should have received both objects in the efficient allocation, but this happens in only $415(72 \%)$ auctions. In $72(12.5 \%)$ auctions one object is inefficiently allocated to a local, and in 89 $(15.5 \%)$ of them both objects are inefficiently allocated to the locals. Note that, in Table 4, we classify the efficiency rates at the auction stage and at the resale stage separately. The percentages of efficient allocations at the auction stage are $40.6 \%$ when the globals do not win any auction, $31.2 \%$ when the globals win only one auction, and $28.2 \%$ when the globals win both of the auctions. Similarly after the resale, those percentages are $32.9 \%, 18.1 \%$ and $49 \%$, respectively.

Tables 2-4 demonstrate that the major source of inefficiency in all the formats arises from allocating an object to a local bidder inefficiently. For example, in VNR, when one local and the global should receive one object each, in $44.4 \%$ of the auctions both locals receive the objects inefficiently. Similarly, when both of the objects need to be allocated to the global, in $28 \%(12.5 \%+15.5 \%)$ of the auctions at least one local receives an object inefficiently. However, when locals should receive both objects efficiently, this happens $89.7 \%$ of the time. The main reason for the local bidders to win inefficiently is due to their aggressive bidding strategy. In the next subsection, we analyze the bidding behavior of the local and global bidders in detail and show that while locals overbid, the globals do not.

The lowest efficiency rate is observed in the auction stage of the SPR. This is mainly due to the observed inefficiencies when the global should have received both objects for the outcome to be efficient. In only $42.4 \%$ of these auctions does the global win both auctions. Given that under the complementarities the global should receive the package efficiently for most of the draws (in 576 out of 900 auctions), the loss of efficiency in this case affects the overall efficiency rate of SPR at the auction stage. At the resale stage of SPR, the locals who win the auction inefficiently sell the objects to the global, and the efficiency rate of SPR improves to VNR's rate. 
Table 2: Efficiency Leaks in VNR Format

\begin{tabular}{l|ccc|cccc}
\hline \multirow{2}{*}{ Observed Outcomes } & \multicolumn{6}{|c}{ Efficient Outcomes } \\
\cline { 2 - 8 } & Local-Local & LG/GL & Global-Global & \multicolumn{5}{c}{ Local-Local } & LG/GL & Global-Global & Total \\
\hline \multirow{2}{*}{ Local-Local } & 234 & 28 & 89 & $\mathbf{8 9 . 7}$ & 44.4 & 15.5 & 39.0 \\
LG/GL & 16 & 31 & 72 & 6.1 & $\mathbf{4 9 . 2}$ & 12.5 & 13.2 \\
Global-Global & 11 & 4 & 415 & 4.2 & 6.3 & $\mathbf{7 2 . 0}$ & 47.8 \\
& & & & & & & \\
Total & 261 & 63 & 576 & 100.0 & 100.0 & 100.0 & 100.0 \\
\hline
\end{tabular}

Table 3: Efficiency Leaks in SPNR Format

\begin{tabular}{l|ccc|cccc}
\hline \multirow{2}{*}{ Observed Outcomes } & \multicolumn{7}{|c}{ Efficient Outcomes } \\
\cline { 2 - 8 } & \multicolumn{3}{|c}{ Count } & \multicolumn{5}{c}{$\%$} \\
\hline \multirow{2}{*}{ Local-Local } & 218 & 17 & 40 & $\mathbf{8 3 . 5}$ & 27.0 & 6.9 & 83.5 \\
LG/GL & 30 & 39 & 170 & 11.5 & $\mathbf{6 1 . 9}$ & 29.5 & 11.5 \\
Global-Global & 13 & 7 & 366 & 5.0 & 11.1 & $\mathbf{6 3 . 5}$ & 5.0 \\
& 261 & 63 & 576 & 100.0 & 100.0 & 100.0 & 100.0 \\
\hline
\end{tabular}

Table 4: Efficiency Leaks in SPR Format

\begin{tabular}{c|ccc|cccc}
\hline \multirow{2}{*}{ Observed Outcomes } & \multicolumn{6}{|c}{ Efficient Outcomes } \\
\cline { 2 - 7 } & \multicolumn{5}{|c|}{ Count } & \multicolumn{5}{c}{$\%$} \\
& Local-Local & LG/GL & Global-Global & Local-Local & LG/GL & Global-Global & Total \\
\hline Local-Local & & & & & & \\
Auction Stage & 219 & 22 & 124 & $\mathbf{8 3 . 9}$ & 34.9 & 21.5 & 40.6 \\
Resale Stage & 222 & 19 & 55 & $\mathbf{8 5 . 1}$ & 30.2 & 9.5 & 32.9 \\
LG/GL & & & & & & & \\
Auction Stage & 33 & 40 & 208 & 12.6 & $\mathbf{6 3 . 5}$ & 36.1 & 31.2 \\
Resale Stage & 33 & 41 & 89 & 12.6 & $\mathbf{6 5 . 1}$ & 15.5 & 18.1 \\
Global-Global & & & & & & & \\
Auction Stage & 9 & 1 & 244 & 3.4 & 1.6 & $\mathbf{4 2 . 4}$ & 28.2 \\
Resale Stage & 6 & 3 & 432 & 2.3 & 4.8 & $\mathbf{7 5 . 0}$ & 49.0 \\
& & & & & & & \\
Total & 261 & 63 & 576 & 100.0 & 100.0 & 100.0 & 100.0 \\
\hline
\end{tabular}




\section{Bidding Behavior:}

The globals' bids for single objects are mostly symmetric in all formats. The percentages of auctions where globals' bids in different markets are the same are $56.8 \%$, $76.6 \%$, and $71.2 \%$ for VNR, SPNR, and SPR, respectively. Furthermore, the percentages of auctions where globals' bids in different markets differ from each other by at most 5 ECUs are $79 \%, 87.6 \%$, and $86.1 \%$, respectively for VNR, SPNR, and SPR. The average absolute difference between the two single-object bids of a global is 5.1, 3.1 and 3.9, respectively for VNR, SPNR, and SPR.

In all formats, the median bids as well as the frequencies of winning are nondecreasing with signals. This is in line with the monotone strategy of VNR and SPNR; however, it also indicates that neither the locals nor the global are using the pooling equilibrium strategies described in Remark 1 in SPR. In Figures 1-3, we plot the raw data, the linear regression as well as the mean and median of bids conditional on signals for each format.

In VNR, although value bidding is the weakly dominant strategy for both the global and the locals, the global is indifferent among bids in a range for certain realization of signals provided that the locals bid their signal. In Figure 1, the equilibrium is not drawn for those signals. In particular, for signals above 50, the global is indifferent among any bids less than her signal for single-object. In the data, $80.5 \%$ of the global's single bids are below her signal when the global's signal is above 50. Similarly, for signals above 66, she is indifferent among any bids more than 200 for the two-object package. Of the globals with signals higher than $66,77.1 \%$ bid more than 200 for twoobject packages. Note also that both mean and median curves are almost linear up to signal 50 in single-object bids of the global in Figure 1, and they are non-linear and below the 45 degree line for signals above 50. Similarly, the mean and median in the package bids of the global are almost linear up to signal 66, and they are above 200 after signal 66.

The bid regressions for VNR are presented in Table 5. The global's two-object package bids are in line with the theoretical prediction. In the regression analysis 
restricted to signals less than 67 , the test of the constant being zero and the coefficient of the signal being equal to 3 is not rejected ( $\mathrm{p}=0.170$ ). The global's single-object bids are mostly less than the value of the single object. We reject the hypothesis that the coefficient of the signal is significant and equal to 1 and the rest is zero in the regression for the globals' single-object bids $(\mathrm{p}=0.000)$. On the other hand, locals tend to bid more than the equilibrium prediction. In Table 5, the coefficient of the signal is more than 1 for the local $(\mathrm{p}=0.000)$. This can be explained by joy of winning (see e.g. Cooper and Fang (2008)).

The joy of winning has an interesting implication for the global bidders in VNR. For example, say the global's signal is 30 , and the locals bid 10 and 70 . If the global bids truthfully, she wins only one item, but by underbidding for the single items, she will win two items. Assuming that she enjoys winning two items more than winning one item, she may want to underbid on single item and not do so on the package. This is what we see in our VNR data. Nevertheless, while joy of winning explanation would predict overbidding for the packages as well, as in Chen and Takeuchi (2010), we do not observe overbidding in the package bids. 
Figure 1: Bidding Behavior in VNR Local Bidding

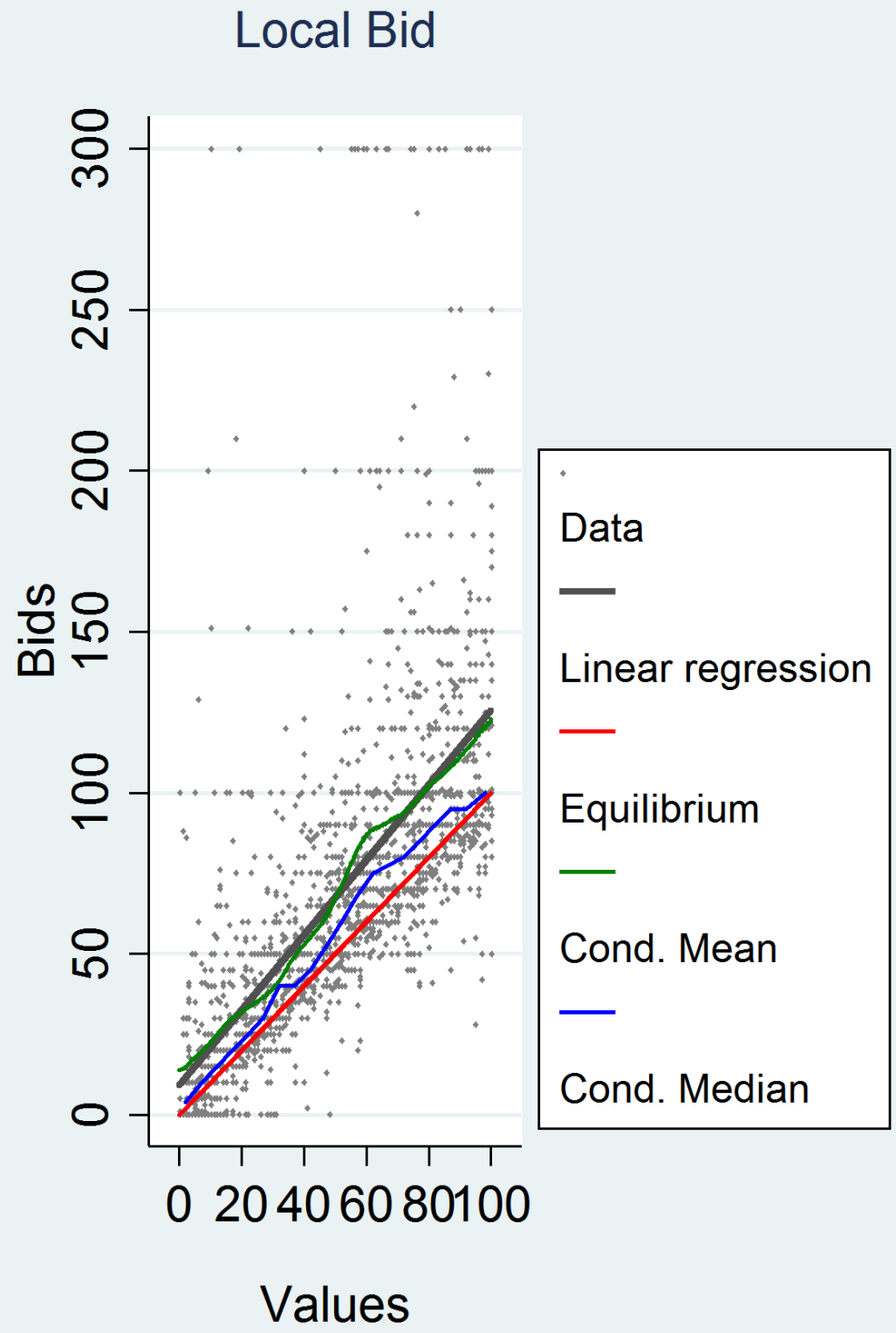


Global Bidding, Single Object

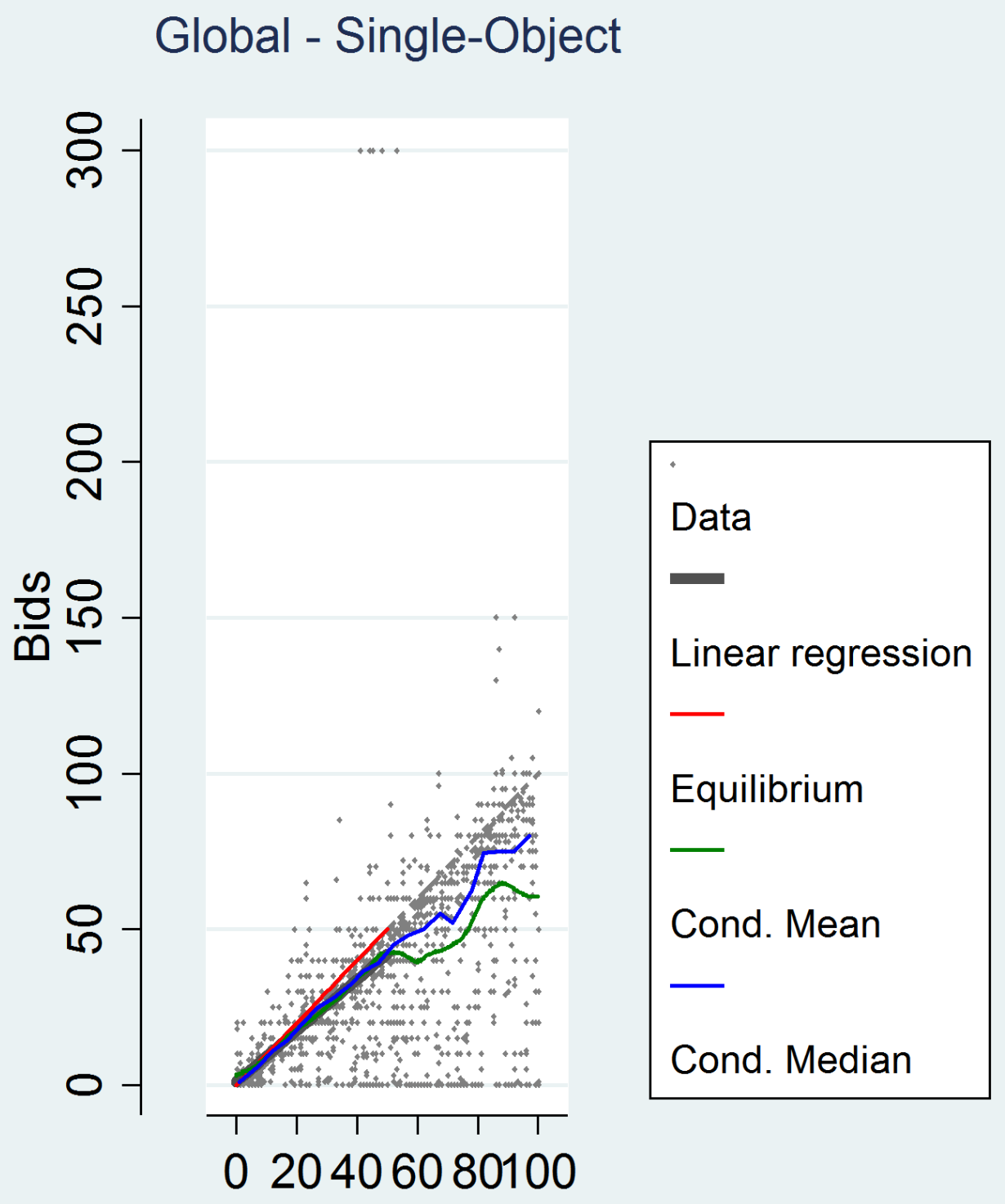

Values 
Global Bidding, Package

Global - Package

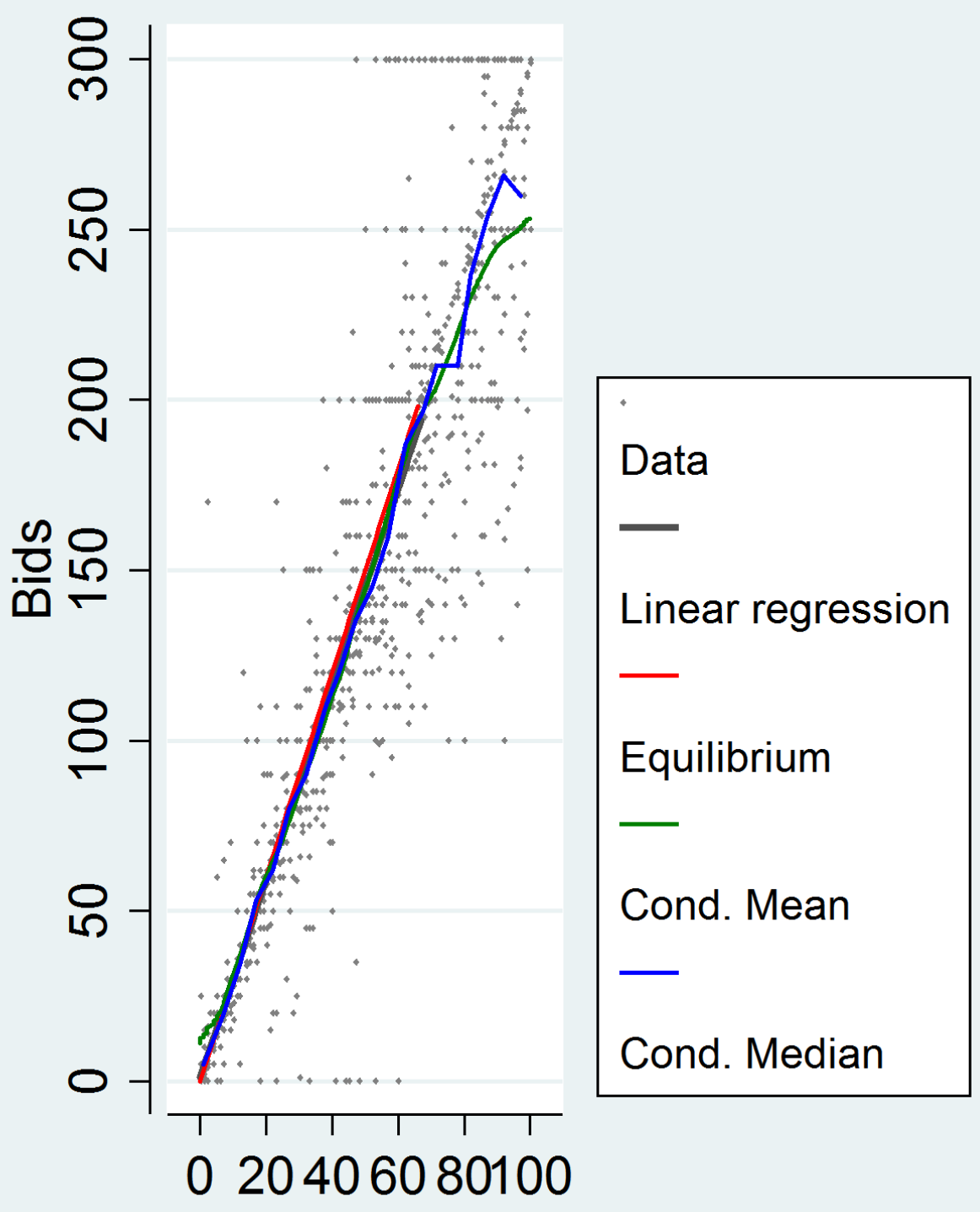

Values 
Table 5: Bid Regressions for VNR

\begin{tabular}{lc|cc}
\hline & Locals' Bids & $\begin{array}{c}\text { Globals' } \\
\text { Single-Object Bids } \\
\text { For Signal }<\mathbf{5 0}\end{array}$ & $\begin{array}{c}\text { Globals' } \\
\text { Package Bids } \\
\text { For Signal }<\mathbf{6 7}\end{array}$ \\
\hline Signal & $\begin{array}{c}1.174 * * * \\
(0.029)\end{array}$ & $0.830^{* * *}$ & $2.885^{* * *}$ \\
Constant & 4.041 & $(0.050)$ & $(0.073)$ \\
N & $(5.701)$ & 1.267 & 3.048 \\
\hline
\end{tabular}

The standard errors are in parentheses. These are regressions with random effect at individual level and fixed effect at session level. $*<0.10$, $* *<0.05$, and $* * *<0.01$.

Table 6: Bid Regressions for SPNR

\begin{tabular}{|c|c|c|}
\hline & Locals' Bid & $\begin{array}{c}\text { Globals' } \\
\ln \left(b_{g}\right) \\
\text { For Signal } \leq \mathbf{5 0} \\
\end{array}$ \\
\hline Signal & $\begin{array}{c}1.115 * * * \\
(0.021)\end{array}$ & \\
\hline $\ln \left(\frac{100}{s_{g}}-1\right)$ & & $\begin{array}{c}-0.755 * * * \\
(0.018)\end{array}$ \\
\hline Constant & $\begin{array}{l}11.118 \\
(6.813)\end{array}$ & $\begin{array}{c}4.369 * * * \\
(0.054)\end{array}$ \\
\hline $\mathbf{N}$ & 1800 & 850 \\
\hline
\end{tabular}

The standard errors are in parentheses. These are regressions with random effect at individual level and fixed effect at session level. $*<0.10, * *<0.05$, and $* * *<0.01$.

Figure 2 shows the behavior in SPNR. The locals bid more aggressively than theory predicts. For local bidders, the coefficient of the signal is significantly higher than 
1 in the regressions in Table $6(\mathrm{p}=0.00)$. This is also consistent with the joy of winning explanation.

By Proposition 4, for the parameters used in the experiment, the equilibrium strategy of the global is as follows: for signals higher than 50, any bid on the interval $[100,300]$ is equally good; for signals less than $50, b_{g}(s)=\frac{100 s}{100-s}$. By log-transforming this equation, we get a linear equation $y=\alpha+\beta \widetilde{\mathrm{s}}$ where $y=\ln b_{g}(s), \alpha=\ln (100)=$ $4.605, \beta=-1$, and $\widetilde{s}=\ln \left(\frac{100}{s}-1\right)$. In the second column of Table 6 , for the realized signals less than 50, we estimated the coefficients of this linear model with random effect at individual level and fixed effect at session level. We find that the coefficient and the constant are significantly different from the theoretical prediction $(\mathrm{p}=0.000)$; hence, the globals' bids are less than what the theory predicts except for very low signals. Also, for globals' signals higher than 50 , only $40.4 \%$ of bids are above 100 . To sum up, as in Vickrey auction, here the global bidders who are interested in more than one object tend not to overbid except for very low signals. This is also observed in Figure 2. Due to complementarities, the global bidders face an exposure problem in SPNR. Although joy of winning motivation may imply overbidding for the globals in SPNR, the exposure problem is more severe since the locals are overbidding. The observed underbidding of the globals in this format can be explained by the globals' fear of paying too much for single item. Moreover, the globals with low signals are unlikely to experience exposure problem and for them the joy of winning may dominate exposure problem effect. Hence, by this explanation those globals may tend to overbid. This is indeed what we see in the data. 
Figure 2: Bidding Behavior in SPNR

Local Bidding

Local Bid

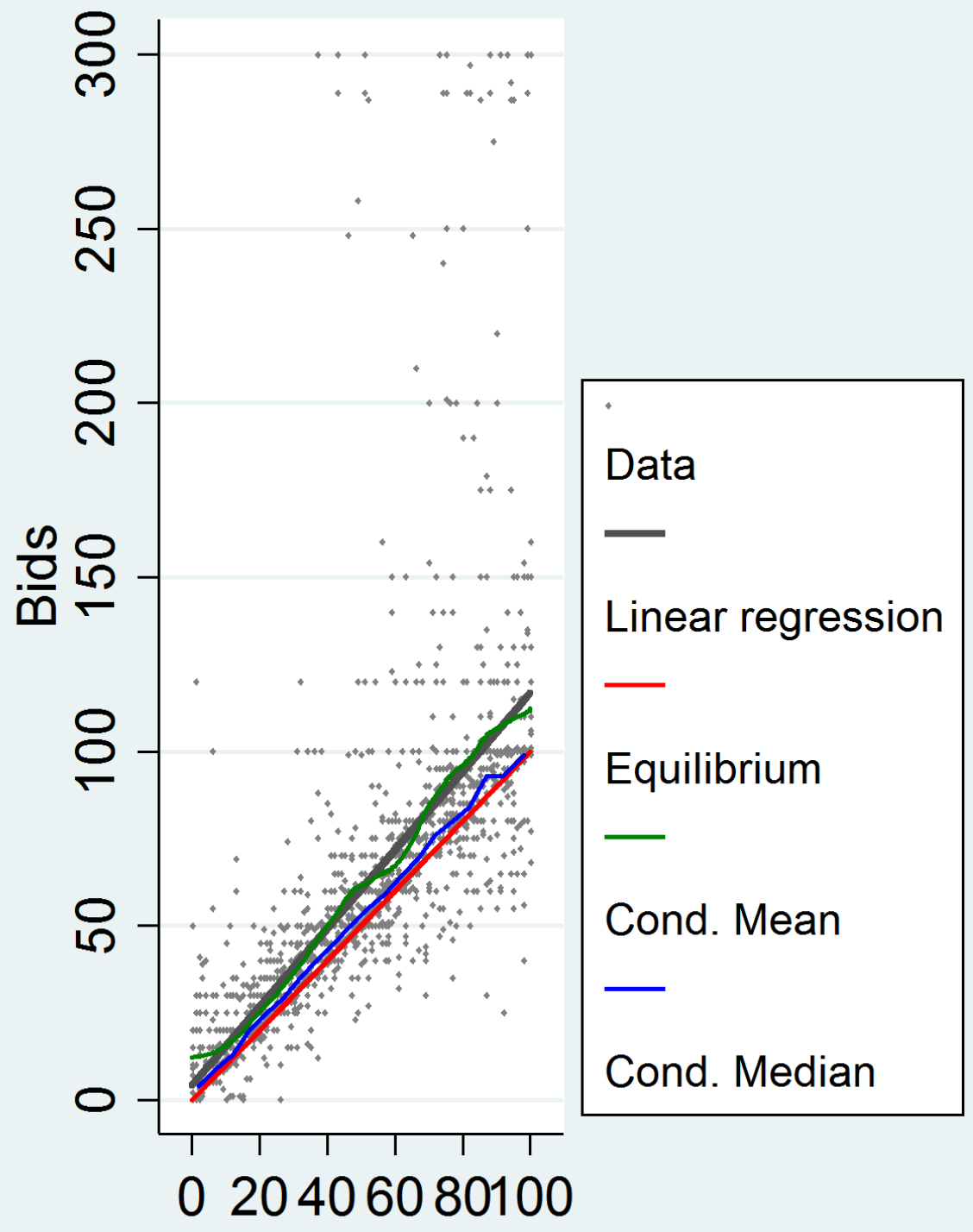

Values 
Global Bidding, Single Object

Global - Single-Object

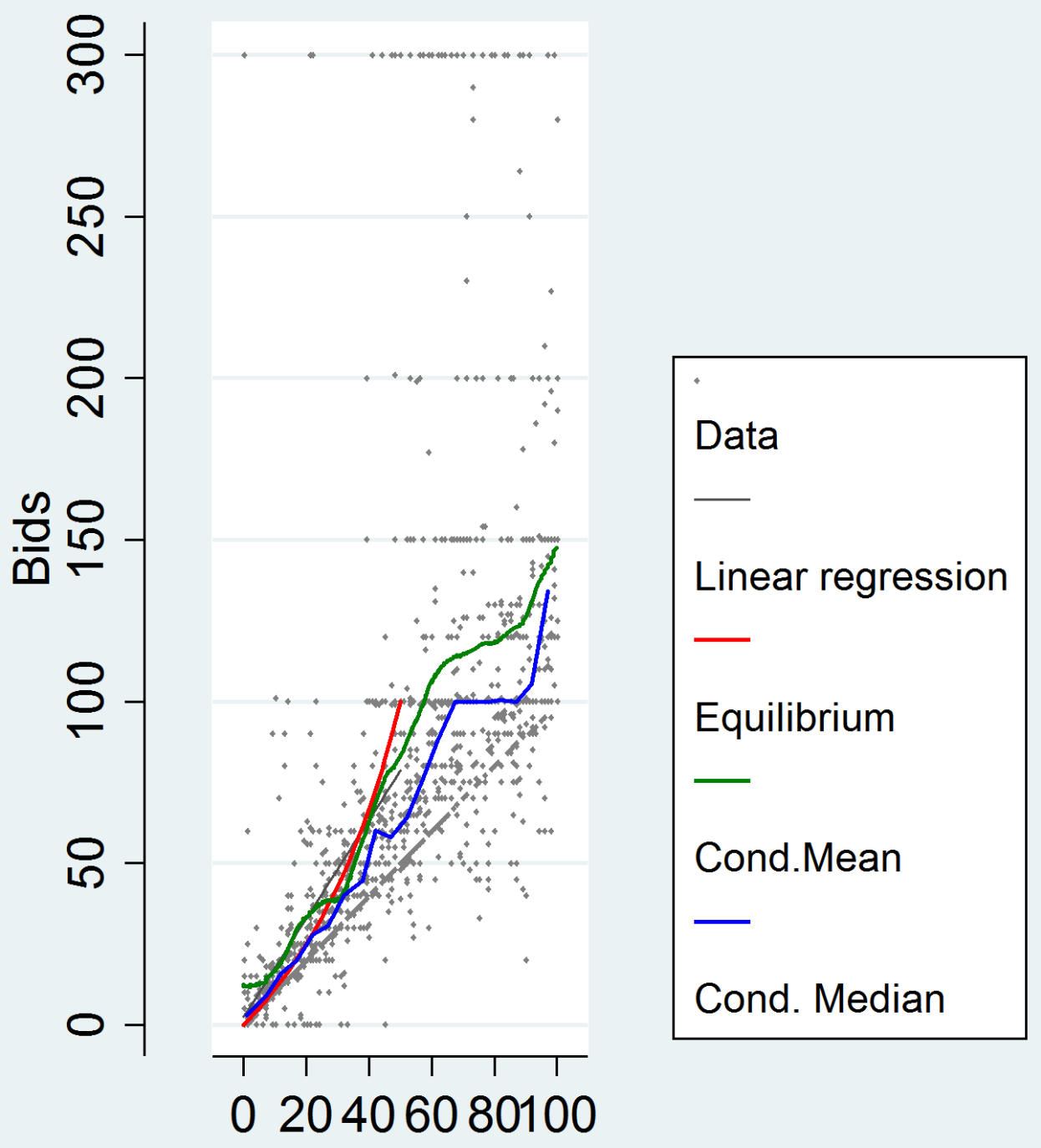

\section{Values}


Figure 3: Bidding Behavior in SPR

Local Bidding

Local Bid

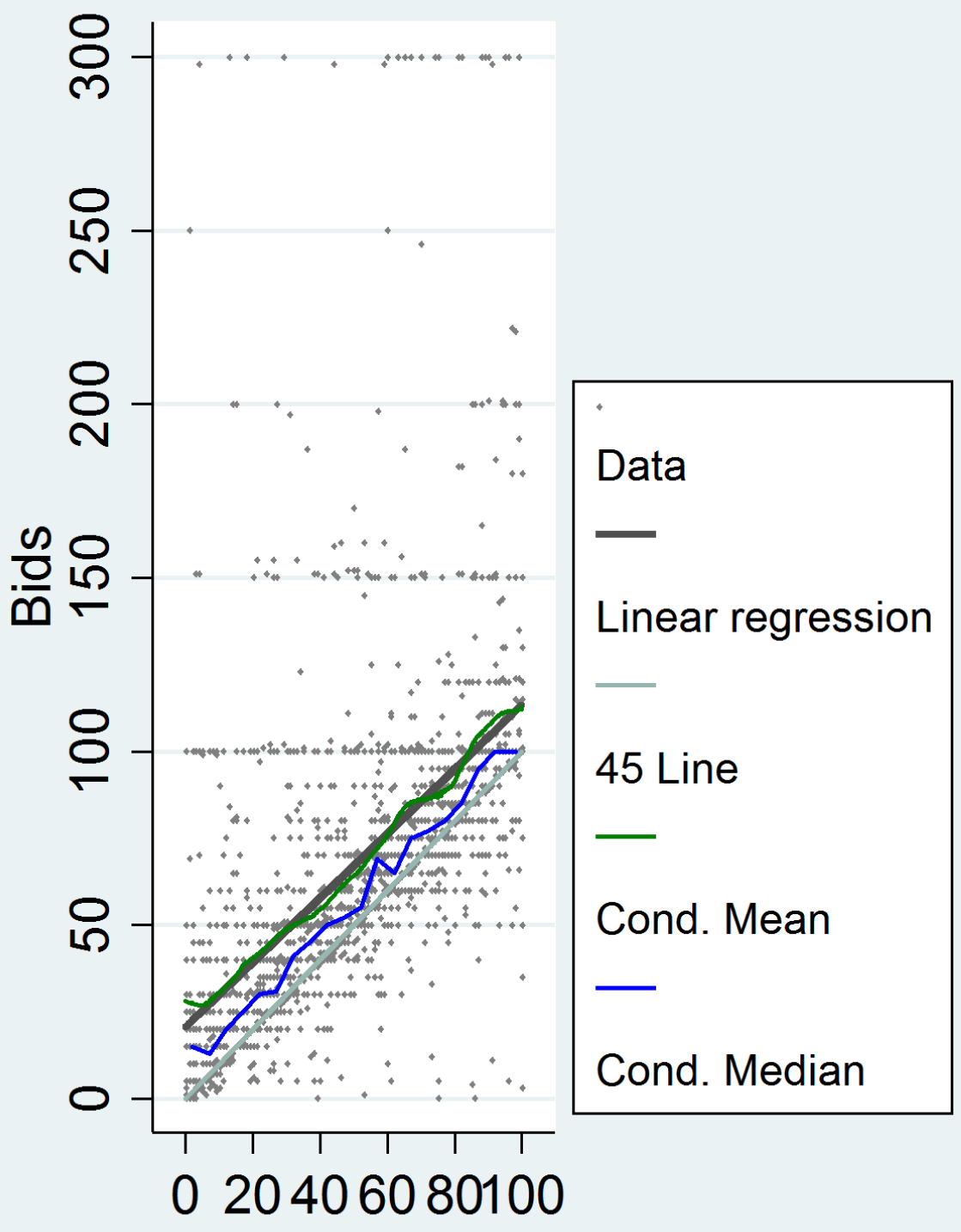

Values 
Global Bidding, Single Object

Global - Single-Object

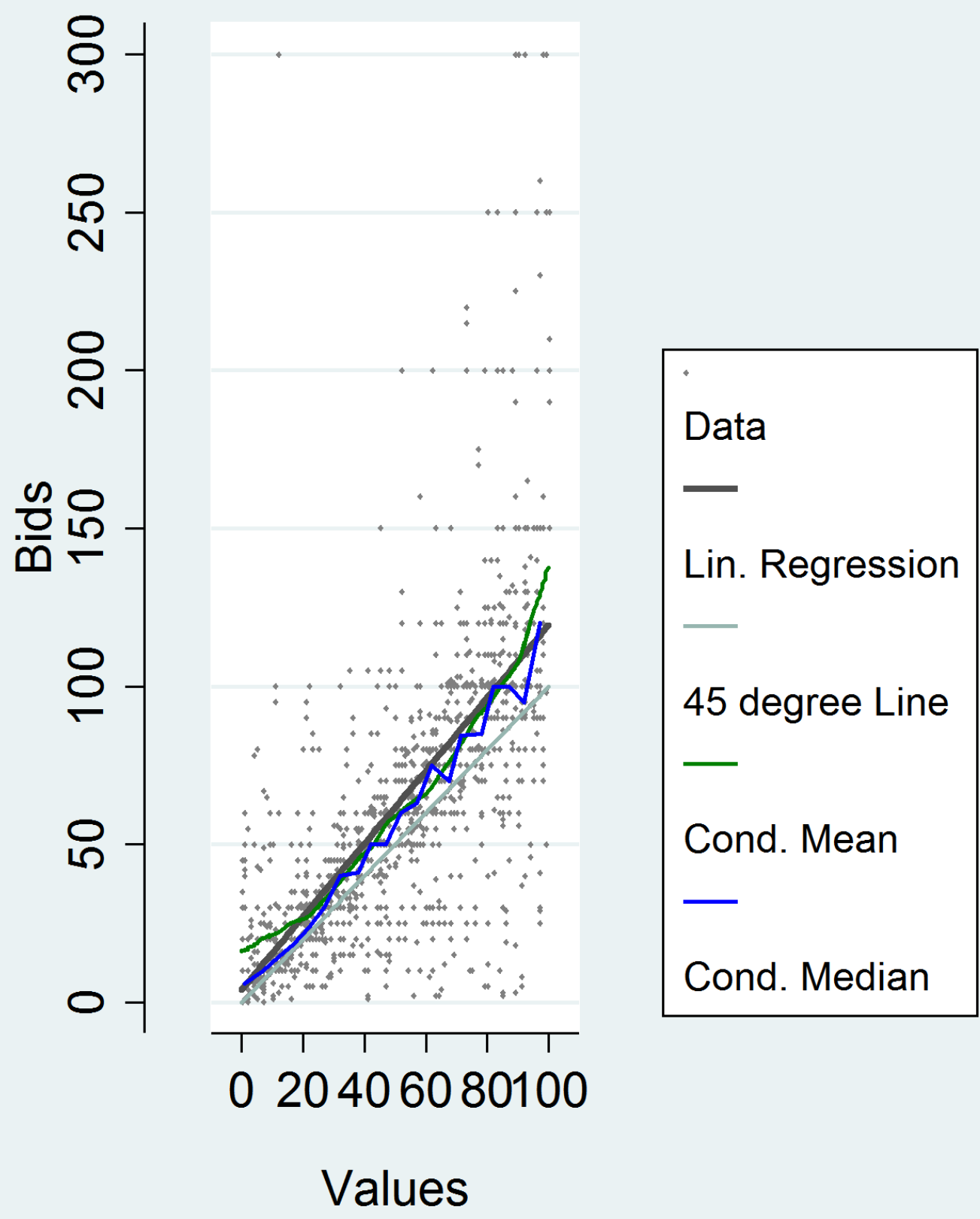


Figure 3 illustrates the bidding behavior of the locals and the globals in SPR. This figure shows that the bidders are not playing a pooling equilibrium where only one type of bidder always wins (see Remark 1). Only 9 out of 1800 local bids were zero, and 15 out of 1800 global bids were $300 .{ }^{14}$ We observe that the locals bid more than their value. Additionally, bidding more than one's value is more pronounced in the SPR format compared to the SPNR ( $\mathrm{p}=0.000$ by Kolmogorov-Smirnov test). On the other hand, the bids of the global in SPR are less than those in SPNR ( $p=0.000$ by Kolmogorov-Smirnov test). One reason for this might be that, given the aggressive behavior of the locals in SPR, the global wants to lower her bid to make the locals think that her value is not much and hence get a lower resale prices from them. ${ }^{15}$

The literature considers nonzero bids of bidders with zero values as speculation since zero valued bidders are the only bidders who are bidding solely to benefit from the resale activity (see e.g. Garratt and Tröger (2006)). In SPR, 87.5\% of the zero valued local bidders submit positive bids. Nevertheless, zero valued bidders may be submitting positive bids without strategically considering the resale activity. For example, even in SPNR, where there is no resale possibility, $68.8 \%$ of the zero valued local bidders submit positive bids. Furthermore, $58.3 \%$ of the zero valued globals submit positive bids in SPR and $50 \%$ in SPNR. We conclude that locals speculate more than the globals when we allow for resale.

Figures 4 and 5 compare, respectively, the bids of locals and globals for different signal bins in SPR and SPNR. ${ }^{16}$ Especially for low signal bins, locals bid more aggressively in SPR than in SPNR. In fact, for all signal ranges up to 70 (except for the range $[41,50])$, the median bid of SPR is significantly above the median bid in the SPNR

\footnotetext{
${ }^{14}$ Also less than $1 \%$ of the global bids for signals less than 50 were higher than 150 .

${ }^{15}$ This explanation is supported by the price regressions in Table 8 where a local's resale price offer increases with the bid of global when the global needs to buy the second object in the resale stage.

${ }^{16}$ The box plots are created using standard techniques. The box represents the interquartile range (IQR); the whiskers extend to the furthest point within $1.5 \times \mathrm{IQR}$; the horizontal line in a box represents the median.
} 
format. On the other hand, the globals' median bids for any signal bin above 20 are significantly lower in SPR than in SPNR.

Figure 4: Locals’ Bids Box-Plots for SPR and SPNR

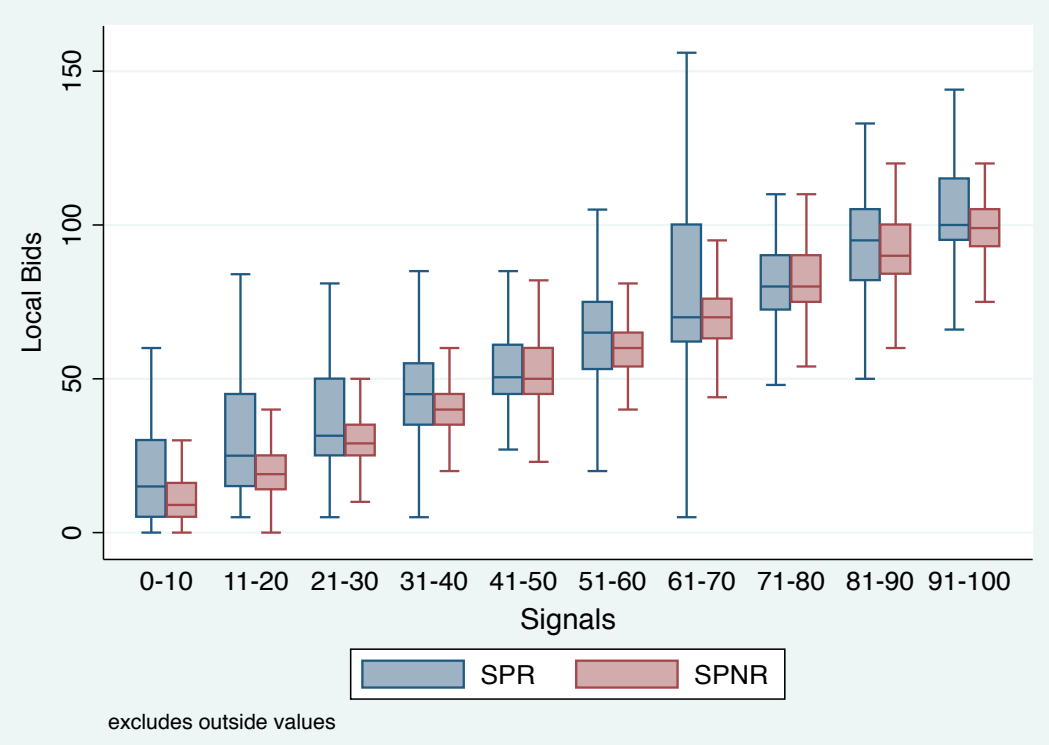

Figure 5: Globals’ Bids Box-Plots for SPR and SPNR

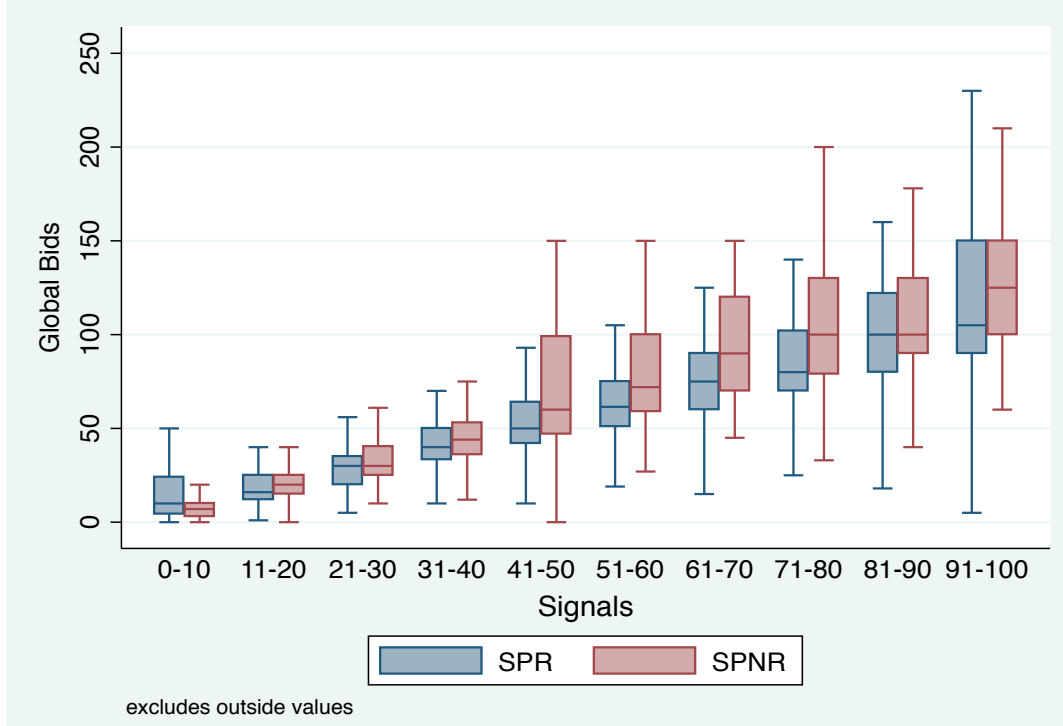




\section{Resale Stage in SPR}

In the resale stage of SPR, the percentage of locals posting profitable offers (i.e. those who asked for resale prices above their own valuation) is $91.7 \%$, and the percentage of rational acceptance (i.e. acceptance of resale terms if and only if doing so was profitable) among all losing bidders is $95.5 \%$. The high rate of rational acceptance of resale offers has been also reported in a context where the seller offers a take-it-or-leaveit price to the losing bidder for the sale of a second unit (see Salmon and Wilson (2008))..$^{17}$

Table 7: Average Resale Prices in SPR

\begin{tabular}{|c|c|c|}
\hline \multirow{2}{*}{ Auction } & \multicolumn{2}{|c|}{ Resale Prices Paid by } \\
\cline { 2 - 3 } Outcome & Global & Locals \\
\hline LL & 70.1 & - \\
& $(4.178)$ & 42.0 \\
LG / GL & 84.0 & $(5.411)$ \\
& $(3.145)$ & 63.5 \\
GG & - & $(7.904)$ \\
\hline
\end{tabular}

The standard errors are in parentheses.

Table 7 reports that higher resale prices are paid by the global when she buys the second object in the post-auction trade than when she goes to resale after losing both objects in the auction. The difference is significant $(\mathrm{p}=0.000$ in the comparison of 70.1 and 84). This finding is intuitive because the locals know that the marginal utility of the second object to the global is higher than the value of single object due to complementarities and they try to extract the additional surplus generated when the global receives the second object. As another implication of the complementarities, after the auctions where only one object is received by the global, the resale price is higher when the global buys than when she sells ( $p=0.000$ in the comparison of 84 and 42). Similarly, when the global offers resale price for both objects, she charges a higher price

\footnotetext{
${ }^{17}$ However, in VR, only $77.5 \%$ of local offers were profitable, while the rational acceptance of resale offers was $90.4 \%$. This result indicates that the major source of the inefficient sales is due to locals offers.
} 
than that when she sells only one object ( $p=0.023$ in the comparison of 42 and 63.5). This is due to the additional value to the global of keeping an object when she has two versus one object.

Table 8 reports the results of the regressions for the locals' resale offers. When the locals win both objects in the auctions, their offers are affected only by their own signals. However, when the locals win only one auction, the offer of the winning local depends not only on her own signal but also on the global's bid in the same market (how much this local paid in the auction) and the bid of the other local (how much the global paid in the other auction that she won). These results suggest that when the global gets only one object in the auction, the local who has the other object is aware that the global must buy it to enjoy the extra payoff of the complementary object. Hence, when setting the price, this power gives an additional motive to the local to take into account all the relevant information. For example, if the global's bid is high, she sets a high price to extract more from the global's payoff from the complementary objects; when the global's bid is low, she thinks that the global may sell it to the other local or be unwilling to pay a high price for the complementary object. The negative and significant coefficient of the other local's bid (i.e. how much the global paid in the market she won) in the third regression of Table 8 may be interpreted as follows: The higher bid by the other local may indicate a high value by that local and therefore the high probability of the global selling to that local rather than buying one more object. As a response, the offering local should lower her price in the resale if she wants the global to buy from her rather than sell to the other local. On the other hand, in the auction stage, if the global does not get any of the objects, a local is no longer the sole seller to the global, and the other local's price plays a role in the decision of the global as well. In this case, the locals just set a profitable price. 
Table 8: Regressions for Locals' Resale Offers in SPR

\begin{tabular}{lccc}
\hline & $\begin{array}{c}\text { First Offer } \\
\text { / Locals win } \\
\text { both objects }\end{array}$ & $\begin{array}{c}\text { Second Offer } \\
\text { / Locals win } \\
\text { both objects }\end{array}$ & $\begin{array}{c}\text { Locals win } \\
\text { only one } \\
\text { object }\end{array}$ \\
\hline Signal & $0.876^{* * *}$ & $0.932 * * *$ & $0.647 * * *$ \\
Global Bid (same object) & $(0.060)$ & $(0.072)$ & $(0.079)$ \\
Global Bid (other object) & 0.150 & -0.042 & $0.453 * * *$ \\
& $(0.148)$ & $(0.190)$ & $(0.129)$ \\
Other Local Bid & -0.127 & -0.034 & 0.158 \\
First (local) Offer & $(0.154)$ & $(0.185)$ & $(0.138)$ \\
& -0.034 & 0.021 & $-0.195 * *$ \\
Constant & $(0.034)$ & $(0.048)$ & $(0.096)$ \\
& & 0.044 & $(0.056)$ \\
& $28.014 * * *$ & $16.391 * *$ & $20.652 * * *$ \\
N & $(6.639)$ & $(7.968)$ & $(6.143)$ \\
\hline The standard errors are in parentheses. These are regressions with random effect at \\
individual level and fixed effect at session level. *<0.10, $* *<0.05$, and $* * *<0.01$.
\end{tabular}

Table 9 reports the regression results for globals' resale offers for the offers not higher than 100 . This is because we assume that any resale offer exceeding a price of 100 can only be made with the intent not to sell. In the regressions, the locals' bid is significant only when the global wins a single object. If a global offers a price less than 100 to sell the single object she has, she wants to extract as much as she believes she can from the losing local based on the information received from the auction stage. When the global wins both auctions and considers selling the objects, only her own signal is significant. In this case, there is room for an exposure problem because the global who aims to sell both objects may end up selling only one. To avoid this, the global sets profitable prices and increases the chance that both locals buy when she wants that. 
Table 9: Regressions for Globals’ Resale Offers in SPR

\begin{tabular}{lcc}
\hline & $\begin{array}{c}\text { Global wins } \\
\text { one object }\end{array}$ & $\begin{array}{c}\text { Global wins } \\
\text { both objects } \\
\text { Both offers }\end{array}$ \\
\hline Signal & $0.569 * * *$ & $0.569 * * *$ \\
Local Bid (same object) & $0.354 * * *$ & $(0.061)$ \\
& $(0.081)$ & -0.014 \\
Local Bid (other object) & 0.014 & $-0.054)$ \\
Other Offer & $(0.033)$ & $(0.044)$ \\
Constant & $-0.080 *$ & \\
& $(0.042)$ & \\
& $27.655 * * *$ & $48.863 * * *$ \\
$\mathrm{~N}$ & $(5.609)$ & $(4.879)$ \\
\hline
\end{tabular}

The games where the offers are less than or equal to 100 . The standard errors are in parentheses. These are regressions with random effect at individual level and fixed effect at session level. $*<0.10, * *<0.05$, and $* * *<0.01$.

\section{Auction Revenue}

Table 10 reports the average observed auction revenue in each treatment as well as the average revenue predicted by the equilibrium for the Vickrey auction and for SPNR, for the draws used in the experiment. Using the 6 independent sessions per treatment, the Mann-Whitney test is used to compare the revenues. There is no significant difference between actual auction revenues in the different formats (for Vickrey vs. SPNR, $z=0.320$ and $p=0.749$; for Vickrey vs. SPR, $z=0.801$ and $p=0.423$; for SPNR vs. SPR: $z=-0.961$ and $p=0.337)$. There is also no significant difference between the actual and predicted revenues of SPNR ( $\mathrm{z}=1.363$ and $\mathrm{p}=0.173)$. However, the actual revenue in Vickrey auctions is significantly higher than that predicted by the theory $(z=1.992$ and $\mathrm{p}=0.046)$.

The Vickrey format generates more revenue than its equilibrium prediction because the locals bid aggressively in the experiment, as argued earlier. Also, in SPR 
auctions, locals bid more aggressively, but globals bid less aggressively than they do in SPNR. Those behaviors have opposite effects on revenue and thus cancel each other out. Hence, these two formats generated similar revenues in the experiment.

Table 10: Average Revenues

\begin{tabular}{ccc}
\hline Treatment & $\begin{array}{c}\text { Theoretical } \\
\text { Revenue }\end{array}$ & Revenue \\
\hline Vickrey & 76.8 & 83.3 \\
& $(2.15)$ & $(3.16)$ \\
SPNR & 78.1 & 81.9 \\
SPR & $(2.32)$ & $(2.02)$ \\
& & 80.3 \\
& & $(4.67)$ \\
\hline
\end{tabular}

Session-clustered S.E. reported in parentheses.

\section{Bidder's Payoff}

Next we compare the formats from the bidders' perspective in Table 11.

Table 11: Bidders' Average Profits

\begin{tabular}{ccccc}
\hline \multirow{2}{*}{ Treatment } & \multicolumn{2}{c}{ Local } & \multicolumn{2}{c}{ Global } \\
\cline { 2 - 5 } & $\begin{array}{c}\text { Theoretical } \\
\text { Payoff }\end{array}$ & Payoff & $\begin{array}{c}\text { Theoretical } \\
\text { Payoff }\end{array}$ & Payoff \\
\hline \multirow{2}{*}{ Vickrey } & 12.28 & 12.70 & 67.80 & 49.99 \\
& $(0.972)$ & $(1.218)$ & $(1.704)$ & $(1.922)$ \\
\hline \multirow{2}{*}{ SPNR } & 11.66 & 12.23 & 67.00 & 51.19 \\
& $(0.981)$ & $(0.705)$ & $(1.737)$ & $(2.472)$ \\
\hline \multirow{2}{*}{ SPR } & & 15.89 & & 48.59 \\
& & $(1.800)$ & & $(1.119)$ \\
\hline
\end{tabular}

Session-clustered S.E. reported in parentheses.

Using independent session averages, Mann-Whitney tests demonstrate that the payoff of the local is the highest in the SPR format. On the other hand, the payoff of the 
global is not significantly different across auction formats (i.e. globals have statistically equivalent mean and median payoffs in all formats, for all signal ranges, see also Figure 6). Figure 7 highlights that the mean and median payoffs of local bidders with signals above 70 are statistically higher in SPR than those in the other two formats.

Figure 6: Globals' Mean and Median Profits

Mean

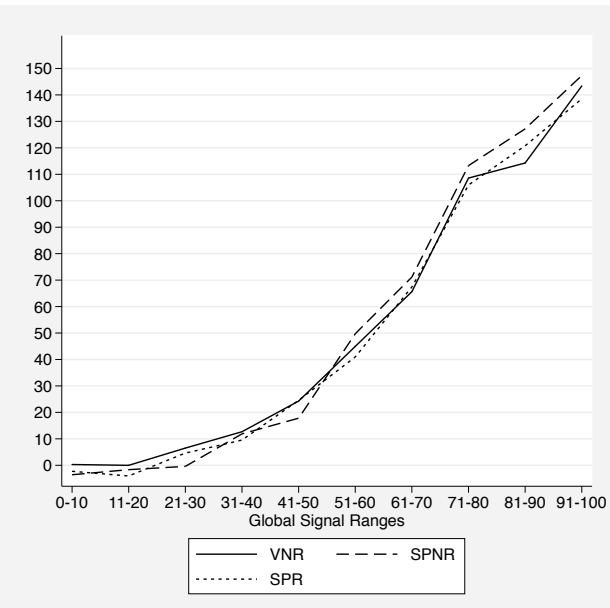

Figure 7: Locals' Mean and Median Profits

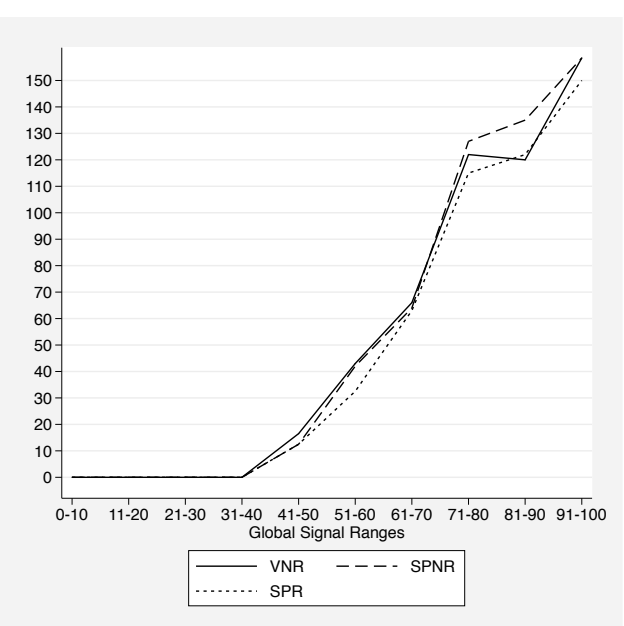

Median
Median

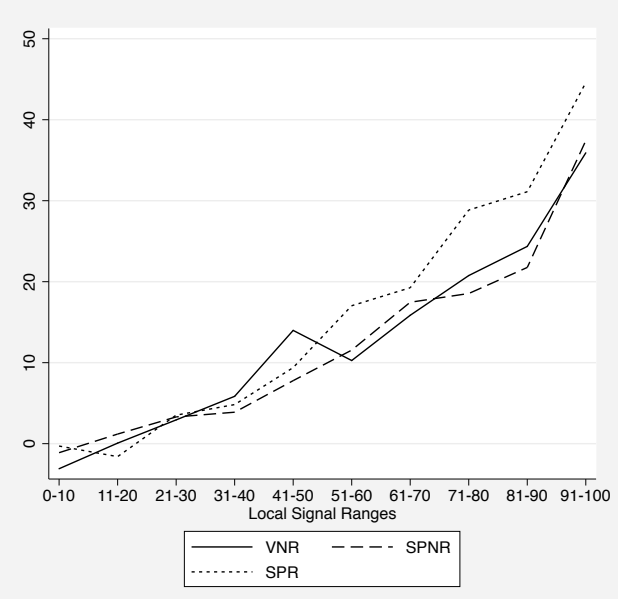

Mean

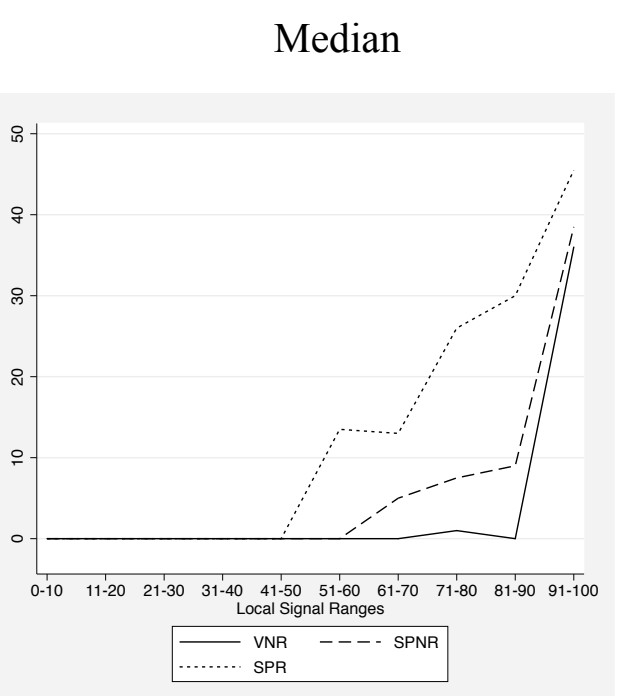




\section{Conclusion}

We have studied multi-object auctions when post-auction resale among bidders is possible. Theoretically, Vickrey auctions (both with and without resale) have an efficient equilibrium; however, in any equilibrium of simultaneous second-price auctions (either with or without resale), the final allocation is not guaranteed to be efficient.

In spite of the theoretical attractiveness of the Vickrey format, in practice, simultaneous second-price auctions are used more often than Vickrey auctions. This is mainly due to the complexity of the Vickrey format (see e.g. Milgrom (1995), Rothkopf (2007)). It is notable that the Vickrey auction does not work so well even in a relatively simple environment. Experimental evidence highlights the trade-off between simple pricing rules that may lead to exposure problems and complex combinatorial auctions (see Bichler, et al. (2014), Brunner, et al (2010)).

In our experiment, we took the efficiency rate of Vickrey as our benchmark, and analyzed the effect of resale on simultaneous second-price auctions. According to our results, although the possibility of resale decreases the efficiency rate in the auction stage of simultaneous second-price auctions, the final efficiency is improved to the observed efficiency rate in a Vickrey auction. Furthermore, in simultaneous second-price auctions, preventing resale hurts efficiency without changing the auction revenue, and allowing resale benefits the locals without diminishing the global bidder's expected payoff. Based on these results, we can conclude that when simultaneous second-price auctions are inevitable or preferred due to simplicity of their implementation, resale markets should be allowed. Nevertheless, in practice, the resale of objects usually leads to transaction costs in bargaining and delays in the actual use of the auctioned objects. It may be important to investigate the effect of such costs on auction stage efficiency rates.

Finally, this paper contributes to the literature by combining theory and experiment. Our experiment highlights the importance of simplicity of the pricing rule that we cannot detect by simply focusing on the theoretical results. Along this line, perhaps rather than Vickrey auction, a simpler pricing rule, such as pay-as-bid package 
auctions, may be better for combinatorial auctions when resale is possible. We leave this fruitful exercise for future research.

\section{References}

Ausubel, Lawrence M. (2004): "An Efficient Ascending-Bid Auction for Multiple Objects," American Economic Review, 94, 1452-1475.

Ausubel, Lawrence M. and Paul Milgrom (2006): "The Lovely but Lonely Vickrey Auctions," In Combinatorial Auctions by Peter Cramton, Yoav Shoham and Richard Steinberg (eds). MIT Press, 17-40.

Ausubel, Lawrence M., and Peter Cramton (1999): "The Optimality of Being Efficient," mimeo.

Bichler, Martin, Jacob K. Goeree, Stefan Mayer, and Pasha Shabalin (2014): "Spectrum Auction Design: Simple Auctions For Complex Sales," Telecommunication Policy, 38 (7), 613-622.

Blume, Andreas, Paul Heidhues, Jonathan Lafky, Johannes Munster and Meixia Zhang (2009): "All Equilibria of the Multi-Unit Vickrey Auction," Games and Economic Behavior, 66, 729-741.

Brunner, Christoph, Jacob K. Goeree, Charles A. Holt, and John O. Ledyard (2010): "An Experimental Test of Flexible Combinatorial Spectrum Auction Formats," AEJ: Microeconomics, 2(1), pp 39-57.

Chen, Yan and Kan Takeuchi (2010): "Multi-Object Auctions with Package Bidding: An Experimental Comparison of iBEA and Vickrey," Games and Economic Behavior, 68 (2): 557 - 579.

Chernomaz, Kirill, and Dan Levin (2012): "Efficiency and Synergy in a Multi-Unit Auction with and without Package Bidding: an Experimental Study," Games and Economic Behavior, 76(2), 611-635.

Cooper, David J., and Hanming Fang (2008): "Understanding Overbidding in Second Price Auctions: An Experimental Study,” Economic Journal, 118, 1572-1595.

Cramton, Peter (2002): "Spectrum Auctions," In Handbook of Telecommunications Economics by Martin Cave, Sumit Majumdar, and Ingo Vogelsang (eds). Elsevier Science B.V., 605-639. 
Cramton, Peter, Yoav Shoham, and Richard Steinberg (2006): "Introduction to Combinatorial Auctions" an introductory essay in Combinatorial Auctions, MIT Press, 113.

De Vries, Sven, and Rakesh V. Vohra (2003): "Combinatorial Auctions: A Survey," INFORMS Journal on Computing, 15 (3). 284-309.

Fischbacher, Urs (2007): "z-Tree: Zurich Toolbox for Ready-made Economic Experiments," Experimental Economics, 10 (2), 171-178.

Flanders, Harley (1973): "Differentiation under the Integral Sign," American Mathematical Monthly, 80 (6), 615-627.

Garratt, Rod, and Thomas Tröger (2006): "Speculation in Standard Auctions with Resale," Econometrica 74, 753-769.

Garratt, Rod, Thomas Tröger and Charles Z. Zheng (2009): "Collusion via Resale," Econometrica, 77, 1095-1136.

Georganas, Sotiris (2011): "English Auctions with Resale: An Experimental Study," Games and Economic Behavior, 73(1), 147-166.

Georganas, Sotiris, and John Kagel (2011): "Asymmetric Auctions with Resale: An Experimental Study,” Journal of Economic Theory, 146(1), 359-371.

Goeree, Jacob, and Yuanchuan Lien (2012): "An Equilibrium Analysis of the Simultaneous Ascending Auction," mimeo.

Gupta, Madhurima, and Bernard Lebrun (1999): "First Price Auctions with Resale," Economics Letters, 64, 181-185

Hafalir, Isa, and Vijay Krishna (2008): "Asymmetric Auctions with Resale," American Economic Review, 98, 87-112.

Haile, Philip A. (1999): “Auctions with Resale,” mimeo.

Haile, Philip A. (2000): "Partial Pooling at the Reserve Price in Auctions with Resale Opportunities," Games and Economic Behavior, 33, 231-248.

Haile, Philip A. (2001): "Auctions with Resale Markets: An Application to U.S. Forest Service Timber Sales," American Economic Review, 91, 399-427.

Haile, Philip (2003): "Auctions with Private Uncertainty and Resale Opportunities," Journal of Economic Theory, 108, 72-110. 
Kagel, John and Dan Levin (1993): "Independent Private Value Auctions: Bidder Behavior in First, Second and Third Price Auctions with Varying Numbers of Bidders," Economic Journal, 103 (419), 868-879.

Kagel, John and Dan Levin (2011): "Auctions: A Survey of Experimental Research, 1995 -2010," to appear in the Handbook of Experimental Economics.

Krishna, Vijay (2002): Auction Theory, San Diego: Academic Press.

Krishna, Vijay, and Motty Perry (2000): “Efficient Mechanism Design,” mimeo.

Krishna, Vijay, and Robert W. Rosenthal (1996): "Simultaneous Auctions with Synergies," Games and Economic Behavior, 17, 1-31.

Laffont, Jean-Jacques, and Jean Tirole (1988): "The Dynamics of Incentive Contracts," Econometrica, 56, 1153-1175.

Lange, Andreas, John A. List, and Michael K. Price (2011): “Auctions with Resale When Private Values are Uncertain: Evidence from the lab and field," International Journal of Industrial Organization, Elsevier, 29(1), 54-64.

Lebrun, Bernard (2010): "First-Price Auctions with Resale and with Outcomes Robust to Bid Disclosure," RAND Journal of Economics, 41 (1), 165-178.

McMillan, John (1994): “Selling Spectrum Rights," Journal of Economic Perspectives, 8, 145-162.

Pagnozzi, Marco (2007): "Bidding to Lose? Auctions with Resale," RAND Journal of Economics, 38, 1090-1112.

Pagnozzi, Marco (2009): "Resale and Bundling in Auctions," International Journal of Industrial Organization, 27, 667-678.

Pagnozzi, Marco (2010): “Are Speculators Unwelcome in Multi-object Auctions?" American Economic Journal: Microeconomics, 2, 97-131.

Pagnozzi, Marco and Saral, Krista Jabs (2013): "Multi-Object Auctions with Resale: An Experimental Analysis," MPRA Paper 43665, University Library of Munich, Germany.

Rothkopf, Michael (2007): "Thirteen Reasons Why the Vickrey-Clarke-Groves Process is not Practical," Operations Research, 55(2):191-197.

Salmon, Timothy C. and Bart J. Wilson (2008): "Second Chance Offers vs. Sequential Auctions: Theory and Behavior," Economic Theory, 34(1), 47-67. 
Vickrey, William (1961): "Counterspeculation, Auctions and Competitive Sealed Tenders," Journal of Finance, 16, 8-37.

Xu, Xiaoshu, Dan Levin, and Lixin Ye (2012): "Auctions with Synergy and Resale," International Journal of Game Theory, 41 (2), 397-426.

Zheng, Charles (2002): “Optimal Auction with Resale,” Econometrica, 70(6), 2197-2224. 


\section{APPENDICES [Not for publication]}

\section{Appendix A - PROOFS}

\section{Proof of Proposition 1.}

For contradiction, assume that there exists an equilibrium with bid profile $\left\{b_{i}\left(s_{i}\right), b_{g_{i}}\left(s_{g}\right)\right\}_{i \leq N}$ such that the auction stage allocates the objects efficiently. Consider a realization of signals such that $s_{i}=0$ for all $i \geq 2$ and $s_{g}=\varepsilon>0$. Notice that by strict superadditivity, $v^{n}(\varepsilon)-v^{n-1}(\varepsilon)>v^{1}(\varepsilon)=\varepsilon$ for $n>1$.

Pick $s_{1}^{*} \in\left(\epsilon, \min _{n \geq 2}\left\{v^{n}(\epsilon)-v^{n-1}(\epsilon)\right\}\right)$. Since $v^{N}(\epsilon)-v^{N-1}(\epsilon)>s_{1}^{*}$, efficiency implies that the global should receive all objects under this signals realization. Since we assumed efficiency of this equilibrium, we should have $b_{g_{1}}\left(s_{g}=\epsilon\right)>b_{1}\left(s_{1}=s_{1}^{*}\right)$. Note that we have not imposed any constraint on $\varepsilon>0$, yet.

Now consider another set of realizations where local 1 and the global have the same signals as before (i.e. $s_{1}=s_{1}^{*}, s_{g}=\varepsilon$ ) but all the other locals receive signal $\bar{s}$ which is the highest possible signal (i.e. $s_{i}=\bar{s}$ for all $i \geq 2$ ).

By the continuity of $v^{n}$ and the strict superadditivity, there exists $\tilde{S}>0$ such that for any $n \geq 2, v^{n}(\tilde{s})<(n-1) \bar{s}$. So pick $\varepsilon \in(0, \tilde{s})$. It is easy to see that for all $k$ such that $0 \leq k \leq N-2$, it is true that $v^{N-k}(\varepsilon)<(N-k-1) \bar{s}<(N-k-1) \bar{s}+s_{1}^{*}$. Then, $k \bar{s}+v^{N-k}(\varepsilon)<(N-1) \bar{s}+s_{1}^{*}$.

This inequality means that for this realization it is efficient to allocate the objects to the locals. Since the equilibrium is assumed to be efficient at the auction stage, the global should lose the auction in market 1 for this realization of signals, i.e. $b_{g_{1}}\left(s_{g}=\varepsilon\right)<$ $b_{1}\left(s_{1}=s_{1}^{*}\right)$. This is a contradiction.

\section{Proof of Proposition 2.}

For contradiction, let us assume there exists an equilibrium $\left\{b_{i}\left(s_{i}\right), b_{g_{i}}\left(s_{g}\right)\right\}_{i \leq N}$ where the allocation after resale stage is efficient for any realization of signals. It can be easily 
shown that all $b .($.$) is weakly increasing since in the efficient equilibrium, the auction$ stage utility of a losing bidder cannot increase after resale. Assume that all b.(.) is right continuous.

By Proposition 1, the allocation at the auction stage is sometimes inefficient. Therefore, there exists a realization $\left(s_{1}, s_{2}, \ldots, s_{g}\right)$ where at least in one market either the global or local loses inefficiently.

Without loss of generality, let us assume that the global loses market 1 inefficiently, i.e. $b_{g_{1}}\left(s_{g}\right)<b_{1}\left(s_{1}\right)$, or $b_{g_{1}}\left(s_{g}\right)=b_{1}\left(s_{1}\right)$ and the global loses as a result of tie-breaking rule. We know that in a neighborhood of $s_{g}, b_{g_{1}}($.$) is strictly increasing. Otherwise, the$ global's signal would not be perfectly revealed and efficiency of the resale stage could not be guaranteed. ${ }^{18}$ Hence, when $b_{g_{1}}\left(s_{g}\right)=b_{1}\left(s_{1}\right)$ and the global loses as a result of tiebreaking rule, consider $s_{g}^{-}$close enough to $s_{g}$ from the left hand side such that the global loses market 1 inefficiently and $b_{g_{1}}\left(s_{g}^{-}\right)<b_{1}\left(s_{1}\right)$.

We require the following Lemma before we can proceed with the proof of Proposition 2.

Lemma 1: There exist $(\underline{b}, \bar{b}) \subset b_{g_{1}}\left(s_{g}-\epsilon, s_{g}+\epsilon\right)$ such that $b_{1}($.$) is strictly increasing$ on $b_{1}^{-1}(\underline{b}, \bar{b})$.

Proof: Assume not. Then there are two cases: (i) local 1 never bids on $b_{g_{1}}\left(s_{g}-\epsilon, s_{g}+\epsilon\right)$ or (ii) Local 1's bid on $b_{g_{1}}\left(s_{g}-\epsilon, s_{g}+\epsilon\right)$ is a step function.

In case (i), for any $s \in\left(s_{g}-\epsilon, s_{g}+\epsilon\right)$ bidding $b_{g_{1}}\left(s_{g}-\epsilon\right)$ is strictly preferred to $b_{g_{1}}(s)$. To see this, notice that $b_{g_{1}}\left(s_{g}-\epsilon\right)$ and $b_{g_{1}}(s)$ lead to the same winning/losing position in the auction. However, by bidding $b_{g_{1}}\left(s_{g}-\epsilon\right)$ the global will buy the object in resale at a lower price when she loses inefficiently. Such a resale trade is a positive probability

\footnotetext{
${ }^{18}$ If Local 1 is winning inefficiently against a global who is playing on the flat part of her bid, then Local 1 must offer a price low enough so that in a neighborhood of $s_{g}$, all global types should accept. Instead, it is better to offer a slightly higher price for Local 1.
} 
event in a neighborhood of $\left(s_{1}, \ldots, s_{N}, s_{g}\right)$. This contradicts with $b_{g_{1}}($.$) being part of an$ equilibrium.

For case (ii), consider $t \equiv \max \left\{b_{1}():. b_{1}(.) \in b_{g_{1}}\left(s_{g}-\epsilon, s_{g}+\epsilon\right)\right\}<b_{1}\left(s_{1}\right)$. So for any global with $s$ such that $b_{g_{1}}^{-1}(t) \leq s \leq s_{g}+\epsilon$, bidding $t$ rather than $b_{g_{1}}(s)$ does not affect her winning/losing position but in the event that she loses inefficiently, she gains in the resale market by making local 1 think that the global has lower signal than s. Such a resale trade is a positive probability event in a neighborhood of $\left(s_{1}, \ldots, s_{N}, s_{g}\right)$. This contradicts with $b_{g_{1}}($.$) being part of an equilibrium.$

Finally, take $\delta$ small enough that $b_{g}$ is strictly increasing on $\left(s_{g}-\delta, s_{g}+\delta\right)$ and $b_{1}$ is strictly increasing on $b_{1}^{-1}\left(b_{g_{1}}\left(s_{g}-\delta\right), b_{g_{1}}\left(s_{g}+\delta\right)\right)$. That is, define $\underline{b} \equiv b_{g_{1}}\left(s_{g}-\delta\right)$ and $\bar{b} \equiv b_{g_{1}}\left(s_{g}+\delta\right)$.

Now, we can continue with the proof of Proposition 2. Next, we show that there exists a profitable deviation for global with signal $s_{g}$. To explain the idea of the proof without complicating the notation too much, we will show it for $N=2$, but the same result can be shown with any $N$.

To simplify the notation, we denote the four possible auction outcomes as $A_{L L}, A_{L G}, A_{G L}$ and $A_{G G}$ when the equilibrium strategies are followed. $A_{x y}$ represents the set of signals where by following the equilibrium strategies bidder $x$ wins market 1 auction and bidder $y$ wins market 2 auction. Analogously, the whole signal space can be partitioned in four regions based on the nature of efficient allocation: $E_{L L}, E_{L G}, E_{G L}$ and $E_{G G}$.

Consider the global's problem when she has signal $s \in\left(s_{g}-\delta, s_{g}+\delta\right)$ and she considers bidding $b_{g}(z)$ where $\in\left(s_{g}-\delta, s_{g}+\delta\right)$. This problem can be written as: 


$$
\begin{aligned}
\operatorname{Max}_{z \in\left(s_{g}-\delta, s_{g}+\delta\right)} \underbrace{\iint_{A_{L L}(z)} l\left(s_{1}, s_{2}, s, z\right) d F\left(\mathbf{s}_{l}\right)}_{L(s, z)}+\underbrace{\iint_{A_{L G}(z)} h^{L G}\left(s_{1}, s_{2}, s, z\right) d F\left(\mathbf{s}_{l}\right)}_{H^{L G}(s, z)} \\
+\underbrace{\iint_{A_{G L}(z)} h^{G L}\left(s_{1}, s_{2}, s, z\right) d F\left(\mathbf{s}_{l}\right)}_{H^{G L}(s, z)}+\underbrace{\iint_{A_{G G}(z)} w\left(s_{1}, s_{2}, s\right) d F\left(\mathbf{s}_{l}\right)}_{W(s)}
\end{aligned}
$$

Where, $A_{L L}(z) \equiv\left\{\left(s_{1}, s_{2}\right):\left(s_{1}, s_{2}, z\right) \in A_{L L}\right\} ; A_{L G}(z) \equiv\left\{\left(s_{1}, s_{2}\right):\left(s_{1}, s_{2}, z\right) \in A_{L G}\right\} ;$ and so on. Also, $l(),. h^{L G}(),. h^{G L}($.$) and w($.$) represents the global's contingent payoffs in$ equilibrium conditional on auction outcomes $A_{L L}, A_{L G}, A_{G L}$ and $A_{G G}$, respectively. Note that $w($.$) does not depend on z$ because, conditional on global winning both objects, locals' beliefs about the global's signal will not play any role in the resale stage. $d F\left(\mathbf{s}_{l}\right)$ denotes $f\left(s_{1}\right) f\left(s_{2}\right) d s_{1} d s_{2}$.

Now, we define $L^{-}(s, z):=L(s, z)$ when $z<s$ and $L^{+}(s, z):=L(s, z)$ when $z>s$ Then,

$$
\begin{gathered}
L^{-}(s, z)=\iint_{A_{L L}(z) \cap E_{L L}(z)} 0 d F\left(\mathbf{s}_{l}\right)+\iint_{A_{L L}(z) \cap\left(E_{L G}(z) \cup E_{G L}(z)\right)}(s-z) d F\left(\mathbf{s}_{l}\right) \\
+\iint_{A_{L L}(z) \cap E_{G G}(z)}\left(v^{2}(s)-v^{2}(z)\right) d F\left(\mathbf{s}_{l}\right)
\end{gathered}
$$

In the equation above, the first term is zero because in that region where the locals win the auctions and it is efficient, there is no trade. The second term has $(s-z)$ inside of the integral because in that region, where locals win the auctions but the global should receive exactly one object in efficient allocation, there is trade in one market and theglobal can keep the difference between the actual surplus and what the local seller believes it is. The third term has $v^{2}(s)-v^{2}(z)$ inside of the integral because in this 
region the global buys both objects in the resale stage and lying gives him the difference between the total surplus and what both local sellers believe as the global's value for the package.

To analyze $\frac{d L^{-}}{d z}$ we use a two-dimensional version of the Leibniz rule (see Flanders, 1973):

$$
\begin{aligned}
\frac{d L^{-}}{d z}= & \iint_{A_{L L}(z) \cap\left(E_{L G}(z) \cup E_{G L}(z)\right)}(-1) d F\left(\mathbf{s}_{l}\right)+\iint_{A_{L L}(z) \cap E_{G G}(z)}\left(-v^{2^{\prime}}(z)\right) d F\left(\mathbf{s}_{l}\right) \\
& +\frac{d}{d t}\left[\int_{A_{L L}(t) \cap\left(E_{L G}(t) \cup E_{G L}(t)\right)}(s-z) d F\left(\mathbf{s}_{l}\right)\right]_{\mathrm{t}=\mathrm{z}} \\
& +\frac{d}{d t}\left[\iint_{A_{L L}(t) \cap E_{G G}(t)}\left(v^{2}(s)-v^{2}(z)\right) d F\left(\mathbf{s}_{l}\right)\right]_{\mathrm{t}=\mathrm{z}}
\end{aligned}
$$

All square brackets converge to zero as $z$ goes to $s$ by the almost everywhere smoothness of the boundaries and the continuity of $v($.$) . Therefore:$

$$
\lim _{z \rightarrow s^{-}} \frac{d L^{-}}{d z}=\iint_{A_{L L} \cap\left(E_{L G} \cup E_{G L}\right)}(-1) d F\left(\mathbf{s}_{l}\right)+\iint_{A_{L L} \cap E_{G G}}\left(-v^{2^{\prime}}(s)\right) d F\left(\mathbf{s}_{l}\right)<0
$$

On the other hand, it is easy to see that $L^{+}(s, z)=0$ because making the locals think that the global's signal is higher than it actually is leads to rejection of locals' offers in the resale stage. This is because the locals will make unacceptable offers to the global when they believe that the global has higher signal than it actually has. Therefore, the global 
keeps the interim payoff from the auction stage, which is zero in this case. Therefore, if the relevant intersections are non-empty: $\lim _{z \rightarrow s^{+}} \frac{d L^{+}}{d z}=0>\lim _{z \rightarrow s^{-}} \frac{d L^{-}}{d z}$.

We now study $H^{L G}($.$) .$

$$
\begin{aligned}
& H^{L G-}(s, z)=\iint_{A_{L G}(z) \cap\left(E_{L L}(z) \cup E_{L G}(z)\right)} \max \left\{s, s_{2}\right\}-b_{2}\left(s_{2}\right) d F\left(\mathbf{s}_{l}\right) \\
& +\iint_{A_{L G}(z) \cap E_{G L}(z)} s-z+\max \left\{z, s_{2}\right\}-b_{2}\left(s_{2}\right) d F\left(\mathbf{s}_{l}\right) \\
& +\iiint_{A_{L G}(z) \cap E_{G G}(z)} v^{2}(s)-v^{2}(z)+\max \left\{z, s_{2}\right\}-b_{2}\left(s_{2}\right) d F\left(\mathbf{s}_{l}\right)
\end{aligned}
$$

Let $\chi$ be the indicator function, which is 1 when the statement is true and zero otherwise. Then,

$$
\begin{aligned}
& \frac{d H^{L G-}}{d z}=\quad \iint_{A_{L G}(z) \cap E_{G L}(z)}\left(-1+\chi\left\{z>s_{2}\right\}\right) d F\left(\mathbf{s}_{l}\right) \\
& +\quad \iint_{A_{L G}(z) \cap E_{G G}(z)}\left(-v^{2^{\prime}}(z)+\chi\left\{z>s_{2}\right\}\right) d F\left(\mathbf{s}_{l}\right) \\
& +\frac{d}{d t}\left[\int_{A_{L G}(t) \cap\left(E_{L L}(t) \cup E_{L G}(t)\right)} \max \left\{s, s_{2}\right\}-b_{2}\left(s_{2}\right) d F\left(\mathbf{s}_{l}\right)\right]_{\mathrm{t}=\mathrm{z}} \\
& +\frac{d}{d t}\left[\int_{A_{L G}(t) \cap E_{G L}(t)} s-z+\max \left\{z, s_{2}\right\}-b_{2}\left(s_{2}\right) d F\left(\mathbf{s}_{l}\right)\right]_{\mathrm{t}=\mathrm{z}} \\
& +\frac{d}{d t}\left[\int_{A_{L G}(t) \cap E_{G G}(t)} v^{2}(s)-v^{2}(z)+\max \left\{z, s_{2}\right\}-b_{2}\left(s_{2}\right) d F\left(\mathbf{s}_{l}\right)\right]_{t=z}
\end{aligned}
$$

Therefore, 


$$
\begin{aligned}
\lim _{z \rightarrow s^{-}} \frac{d H^{L G-}}{d z}= & \iint_{A_{L G}(s) \cap E_{G L}(s)}\left(-1+\chi\left\{s>s_{2}\right\}\right) d F\left(\mathbf{s}_{l}\right) \\
& +\iiint_{A_{L G}(s) \cap E_{G G}(s)}\left(-v^{2^{\prime}}(s)+\chi\left\{s>s_{2}\right\}\right) d F\left(\mathbf{s}_{l}\right) \\
& +\frac{d}{d t}\left[\iint_{A_{L G}(t)} \max \left\{s, s_{2}\right\}-b_{2}\left(s_{2}\right) d F\left(\mathbf{s}_{l}\right)\right]_{\mathrm{t}=\mathrm{s}}
\end{aligned}
$$

Aside,

$$
\lim _{z \rightarrow s^{+}} \frac{d H^{L G^{+}}}{d z}=\frac{d}{d t}\left[\iint_{A_{L G}(t)} \max \left\{s, s_{2}\right\}-b_{2}\left(s_{2}\right) d F\left(\mathbf{s}_{l}\right)\right]_{\mathrm{t}=\mathrm{s}}>\lim _{z>s} \frac{d H^{L G-}}{d z}
$$

The last inequality above holds because the derivative of value function is strictly increasing in , i.e. $v^{2^{\prime}}(s)>v^{1^{\prime}}(s)=1 \geq \chi\left\{s>s_{2}\right\}$.

Similarly, if the relevant intersections are non-empty: $\lim _{z \rightarrow S^{+}} \frac{d H^{G L^{+}}}{d z}>\lim _{z \rightarrow s^{-}} \frac{d H^{G L-}}{d z}$.

Putting all together, for regions where global might lose inefficiently, $\lim _{z \rightarrow s^{+}} \frac{d L^{+}}{d z}+$ $\lim _{z \rightarrow s^{+}} \frac{d H^{L G^{+}}}{d z}+\lim _{z \rightarrow s^{+}} \frac{d H^{G L^{+}}}{d z}>\lim _{z \rightarrow s^{-}} \frac{d L^{-}}{d z}+\lim _{z \rightarrow s^{-}} \frac{d H^{L G-}}{d z}+\lim _{z \rightarrow s^{-}} \frac{d H^{G L-}}{d z}$ necessarily. Therefore, bidding $b_{g}(s)$ cannot be a locally optimal behavior since we assumed that in a neighborhood of $\left(s_{1}, \ldots, s_{N}, s_{g}\right)$ the global loses inefficiently.

Similarly, in this equilibrium, if local 1 loses inefficiently when signals are $\left(s_{1}, \ldots, s_{N}, s_{g}\right)$, one can show that there exists $(\underline{a}, \bar{a}) \subset b_{1}\left(s_{1}-\epsilon, s_{1}+\epsilon\right)$ such that $b_{g_{1}}($. is strictly increasing on $b_{1}^{-1}(\underline{a}, \bar{a})$ (a similar statement to Lemma 1). In a neighborhood 
of $s_{1}$, we can show that the derivative of the expected payoff of local 1 when we approach to $s_{1}$ from right is greater than that from left.

We found that strictly increasing bidding in a neighborhood of signals where inefficient losing is possible is non-optimal, but the efficiency of the resale stage cannot be guaranteed.

\section{Proof of Proposition 3.}

Consider the following strategies: In the auction, locals bid their signals in their markets. The global bids $v^{n}(s)$ for each package with $n$ objects. After the auction, the winning locals may offer some price only if there exists signal $s_{g}$ such that $b_{g_{I}}\left(s_{g}\right)=v^{n}\left(s_{g}\right)$ for any $I \subseteq\{1, \ldots, N\}$ and $|I|=n$.

In the resale market, when the set of winning locals is $A \subseteq\{1, \ldots, N\}$, the resale strategy

of winning local $j$, when she makes the first offer, is $p=v^{N-|A|+1}\left(s_{g}\right)-v^{N-|A|}\left(s_{g}\right)$ only if $p \geq s_{j}$. If she is not the first local who makes an offer then she asks for $v^{N}(\bar{s})$.

In the resale market, when the set of winning locals is $A \subseteq\{1, \ldots, N\}$ and a set of offers $\left\{q_{j}\right\}_{j \in K}$, where $K \subseteq A$, are made to the global, the global will offer $\left\{p_{i}\right\}_{i \in B}$ for $B \subseteq\{1, \ldots, N\} \backslash A$ when global believes $s_{i}=p_{i}$ for $i \in B$ and only if

$$
\sum_{i \in B} p_{i} \geq \max _{\mathrm{C} \subseteq \mathrm{K}} v^{N-|K \cup B|+|C|}\left(s_{g}\right)-v^{N-|A \backslash C|}\left(s_{g}\right)
$$

If such $B$ does not exist, global will not sell in the resale market. The condition above checks whether there exists any set of losing locals, $B$, such that the global is better off when she sells to those locals and buys from a subset, $C$, of winning locals rather than not selling to those locals in set $B$.

Define $\left(s_{1}, \ldots, s_{N}, s_{g}\right):=\operatorname{argmax}_{A \subseteq\{1, \ldots, N\}} v^{N-|A|}\left(s_{g}\right)+\sum_{i \in A} s_{i}$. Hence, $E\left(s_{1}, \ldots, s_{N}, s_{g}\right)$ is the set of locals who receive objects in the efficient allocation.

Suppose locals play using the strategy above. We show next that it is the best response for the global with signal $s_{g}$ to bid $v^{n}\left(s_{g}\right)$ for packages with $n$ objects. The global's payoff from this strategy is $v^{N-|E|}\left(s_{g}\right)-\sum_{i \notin E} s_{i}$. 
Assume that the global deviates and bids in a way that is not in line with any signal according to the locals' equilibrium belief (i.e. \#s such that $b_{g_{I}}=v^{n}(s)$ for any $I \subseteq\{1, \ldots, N\}$ and $|I|=n$.) In this case, the winning locals will not sell to the global but the global may sell some objects at a price that is equal to the sum of the values of the buying locals. Let $A$ be the set of locals who holds some objects after resale stage. Then,

$$
\begin{aligned}
& v^{N-|A|}\left(s_{g}\right)-\sum_{i \notin A} s_{i}=v^{N-|A|}\left(s_{g}\right)-\sum_{i \notin A} s_{i}+\sum_{i \in A} s_{i}-\sum_{i \in A} s_{i} \\
\leq & v^{N-|E|}\left(s_{g}\right)-\sum_{i \notin A} s_{i}+\sum_{i \in E} s_{i}-\sum_{i \in A} s_{i} \leq v^{N-|E|}\left(s_{g}\right)-\sum_{i \notin E} s_{i}
\end{aligned}
$$

The left hand side above is the global's payoff when she deviates; the right hand side is the global's payoff when she bids her value for the packages truthfully.

Now assume that the global deviates and bids as if her signal is $z \neq s_{g}$. Note that if $E\left(s_{1}, \ldots, s_{N}, z\right)=E\left(s_{1}, \ldots, s_{N}, s_{g}\right)$, then no trade occurs and, similar to the above argument, the global cannot be better off in the auction stage either. If, instead, $\tilde{E} \equiv E\left(s_{1}, \ldots, s_{N}, z\right) \neq E\left(s_{1}, \ldots, s_{N}, s_{g}\right)=: E$, then no winning local makes an offer to the global since from a winning local $i$ 's perspective, the outcome is efficient and therefore the highest price the global can pay is $v^{|\{N \backslash \tilde{E}\}|+1}(z)-v^{|\{N \backslash \tilde{E}\}|}(z) \leq s_{i}$. To see this, note that

$v^{N-|\tilde{E}|}(z)+\sum_{i \in \tilde{E}} S_{i} \geq v^{N-|K|}(z)+\sum_{i \in K} S_{i}$ for all $K \subseteq\{1, \ldots, N\}$.

In particular, for $K=\tilde{E} \backslash\{i\}, v^{N-|\tilde{E}|}(z)+\sum_{i \in \tilde{E}} S_{i} \geq v^{N-|\tilde{E}|+1}(z)+\sum_{i \in \tilde{E} \backslash\{i\}} S_{i}$

Therefore, $v^{N-|\tilde{E}|+1}(z)-v^{N-|\tilde{E}|}(z) \leq s_{i}$. Hence, local $i$ will not sell. This implies that the only benefit for the global can come from selling some objects.

Consider any $A \subset N \backslash \widetilde{E}$ (a subset of losing locals in the after deviation outcome of the auction.) The global can sell to locals in $A$ at most at $\sum_{i \in A} s_{i}$. If some resale trade takes place

Global's payoff after resale $\leq \sum_{i \in A} s_{i}+v^{N-|A \cup \tilde{E}|}\left(s_{g}\right)-\sum_{i \in N \backslash \tilde{E}} S_{i}$ 


$$
\begin{aligned}
& =\sum_{i \in A} s_{i}+v^{N-|A \cup \tilde{E}|}\left(s_{g}\right)-\sum_{i \in N \backslash \tilde{E}} s_{i}+\left(\sum_{i \in \tilde{E}} s_{i}-\sum_{i \in \tilde{E}} s_{i}\right) \\
& =v^{N-|A \cup \tilde{E}|}\left(s_{g}\right)+\left(\sum_{i \in A \cup \tilde{E}} s_{i}-\sum_{i \in N} s_{i}\right) \\
& \leq v^{N-|E|}\left(s_{g}\right)+\left(\sum_{i \in E} s_{i}-\sum_{i \in N} s_{i}\right) \\
& \leq v^{N-|E|}\left(s_{g}\right)-\sum_{i \in N \backslash E} s_{i} \\
& =\text { Global's payoff from the equilibrium strategy }
\end{aligned}
$$

Therefore, there does not exist a profitable deviation for the global.

Next, consider a local, say local 1 . Assume that all the bidders except local 1 follow the equilibrium strategies. Let us define $E^{-1}:=\arg \max _{\mathrm{A} \subseteq N \backslash\{1\}} v^{N-|A|}\left(s_{g}\right)+\sum_{i \in A} s_{i}$.

Case 1: If $1 \in E$ (i.e. if local 1should receive an object in the efficient allocation.)

If local 1 bids $s_{1}$, then she wins and her payoff is:

$$
s_{1}-\left[\left(v^{N-\left|E^{-1}\right|}\left(s_{g}\right)+\sum_{i \in E^{-1}} s_{i}\right)-\left(v^{N-|E|}\left(s_{g}\right)+\sum_{i \in E \backslash\{1\}} s_{i}\right)\right]
$$

If, instead, local 1 bids $b_{1}>s_{1}$ she wins and does not trade later since $1 \in E$. Her payoff is: $s_{1}-\left[\left(v^{N-\left|E^{-1}\right|}\left(s_{g}\right)+\sum_{i \in E^{-1}} s_{i}\right)-\left(v^{N-|\tilde{E}|}\left(s_{g}\right)+\sum_{i \in \tilde{E} \backslash\{1\}} s_{i}\right)\right]$

Where $\tilde{E}$ denotes the current allocation when local 1 bids $b_{1}$. However, efficiency implies that bidding truthfully will give a weakly better payoff to local 1 than bidding $b_{1}$.

Now consider a deviation of local 1 where she bids below her signal, i.e. $b_{1}<s_{1}$. Let $\tilde{E}:=E\left(b_{1}, s_{2}, \ldots, s_{N}, s_{g}\right)$

Case 1.1: If $1 \in \tilde{E}$ then 1 will not trade later, and her auction payment when she bids $b_{1}$ is not less than what it would be if she bid $s_{1}$. Therefore, it cannot be a profitable deviation.

Case 1.2: If $1 \notin \widetilde{E}$, we need to check whether local 1 can buy from the global and be better off. As analyzed in the global's strategy above, the winning locals will not make 
any offer since they believe that the equilibrium is played and the allocation is efficient. Local 1 may buy from the global in resale since the current allocation is not efficient. For any subset of losing locals that contain local 1 , i.e. $\forall B \subseteq\{1, \ldots, N\} \backslash \tilde{E}$ such that $1 \in B$, the global thinks that the locals in $B$ is are able to pay $\sum_{i \in B \backslash\{1\}} s_{i}+b_{1}$ in total. Note that $v^{N-|\tilde{E}|}\left(s_{g}\right)+\sum_{i \in \tilde{E}} s_{i} \geq v^{N-|B \cup \tilde{E}|}\left(s_{g}\right)+b_{1}+\sum_{i \in B \cup \tilde{E} \backslash\{1\}} s_{i}$ by the definition of $\tilde{E}$. Then

$$
v^{N-|\tilde{E}|}\left(s_{g}\right)-v^{N-|B \cup \tilde{E}|}\left(s_{g}\right) \geq b_{1}+\sum_{i \in B \backslash\{1\}} s_{i}
$$

Hence, the global will not sell to any subset of losing locals that include local 1 at the resale stage. Therefore, the local 1's payoff from the deviation is zero, which is not profitable.

Case 2: If $1 \notin E$. Then local 1 loses market 1 when she bids $s_{1}$ and her payoff is zero.

If she bids $b_{1}<s_{1}$, she loses and the global thinks that local will pay at most $b_{1}$. Note that by definition of $E$

$v^{N-|E|}\left(s_{g}\right)+\sum_{i \in E} s_{i} \geq v^{N-|E|-1}\left(s_{g}\right)+\sum_{i \in E} s_{i}+s_{1}$.

Then $v^{N-|E|}\left(s_{g}\right)-v^{N-|E|-1}\left(s_{g}\right) \geq s_{1}>b_{1}$ and the global will not sell at any price that she thinks that local 1 is willing to pay.

If local 1 bids $b_{1}>s_{1}$ and she loses, the global will offer at least $b_{1}$, which will not be accepted by local 1 and then local 1's payoff will be zero.

If she bids $b_{1}>s_{1}$ and she wins then she can sell it at $v^{N-|\tilde{E}|+1}\left(s_{g}\right)-v^{N-|\tilde{E}|}\left(s_{g}\right)$. In this event, her payoff is

$$
\begin{gathered}
v^{N-|\tilde{E}|+1}\left(s_{g}\right)-v^{N-|\tilde{E}|}\left(s_{g}\right)-\left[\left(v^{N-\left|E^{-1}\right|}\left(s_{g}\right)+\sum_{i \in E^{-1}} s_{i}\right)-\left(v^{N-|\tilde{E}|}\left(s_{g}\right)+\sum_{i \in \tilde{E} \backslash\{1\}} s_{i}\right)\right] \\
=v^{N-|\tilde{E}|+1}\left(s_{g}\right)+\sum_{i \in \tilde{E} \backslash\{1\}} s_{i}-\left(v^{N-\left|E^{-1}\right|}\left(s_{g}\right)+\sum_{i \in E^{-1}} s_{i}\right)
\end{gathered}
$$




$$
\leq 0 \text { (by definition of } E^{-1} \text { ) }
$$

and zero was her payoff if she bid $s_{1}$. Recall that zero was local 1's payoff when she bid $S_{1}$, truthfully. The last inequality above holds because $E^{-1}$ achieves the highest total bid among all the allocations where the global receives the object in market 1 .

Cases 1 and 2 together show that for local 1 there is no profitable deviation from truthful signal bidding, while other bidders follow the equilibrium strategies.

\section{Proof of Proposition 4.}

Each local is participating in a second-price auction for a single privately valued object. Therefore, truthful signal bidding is their weakly dominant strategy.

Define $\Pi\left(b_{g_{1}}, b_{g_{2}} ; s\right)$ as the global's expected payoff of bidding $b_{g_{1}}$ and $b_{g_{2}}$ in markets 1 and 2 , respectively when her signal is $s$. Then

$$
\begin{aligned}
\Pi\left(b_{g_{1}}, b_{g_{2}} ; s\right)= & \frac{b_{g_{1}}}{100} \frac{b_{g_{2}}}{100}\left(3 s-E\left[p \mid b_{g_{1}}\right]-E\left[p \mid b_{g_{2}}\right]\right) \\
& +\frac{b_{g_{1}}}{100}\left(1-\frac{b_{g_{2}}}{100}\right)\left(s-E\left[p \mid b_{g_{1}}\right]\right)+\frac{b_{g_{2}}}{100}\left(1-\frac{b_{g_{1}}}{100}\right)\left(s-E\left[p \mid b_{g_{2}}\right]\right) \\
= & \frac{b_{g_{1}}}{100} \frac{b_{g_{2}}}{100} s+\frac{b_{g_{1}}}{100} \Delta^{1}+\frac{b_{g_{2}}}{100} \Delta^{2}
\end{aligned}
$$

where $E\left[p \mid b_{g_{i}}\right]$ is the expected auction price when the global wins in market $i$ by bidding $b_{g_{i}}$, and $\Delta^{i}=s-E\left[p \mid b_{g_{i}}\right]$.

First, we show that the global's optimal bidding function is object-symmetric (i.e. $\left.b_{g_{1}}=b_{g_{2}}\right)$. For contradiction, suppose not, and assume without loss of generality that $b_{g_{1}}>b_{g_{2}}$ at the optimum and $\Pi\left(b_{g_{1}}, b_{g_{2}} ; s\right)>\Pi\left(b_{g_{2}}, b_{g_{2}} ; s\right)$. Then the following hold:

$$
\frac{b_{g_{1}}}{100} \frac{b_{g_{2}}}{100} s+\frac{b_{g_{1}}}{100} \Delta^{1}+\frac{b_{g_{2}}}{100} \Delta^{2}>\left(\frac{b_{g_{2}}}{100}\right)^{2} s+2 \frac{b_{g_{2}}}{100} \Delta^{2}
$$




$$
\begin{aligned}
& \Leftrightarrow\left(\frac{b_{g_{1}}}{100} \frac{b_{g_{2}}}{100}-\left(\frac{b_{g_{2}}}{100}\right)^{2}\right) s+\frac{b_{g_{1}}}{100} \Delta^{1}>\frac{b_{g_{2}}}{100} \Delta^{2} \\
& \left.\Leftrightarrow\left(\left(\frac{b_{g_{1}}}{100}\right)^{2}-\frac{b_{g_{1}}}{100} \frac{b_{g_{2}}}{100}\right) s+\frac{b_{g_{1}}}{100} \Delta^{1}>\frac{b_{g_{2}}}{100} \Delta^{2} \quad \text { (since } b_{g_{1}}>b_{g_{2}}\right) \\
& \Rightarrow\left(\frac{b_{g_{1}}}{100}\right)^{2} s+2 \frac{b_{g_{1}}}{100} \Delta^{1}>\frac{b_{g_{1}}}{100} \frac{b_{g_{2}}}{100} s+\frac{b_{g_{1}}}{100} \Delta^{1}+\frac{b_{g_{2}}}{100} \Delta^{2} \\
& \Leftrightarrow \Pi\left(b_{g_{1}}, b_{g_{1}} ; s\right)>\Pi\left(b_{g_{1}}, b_{g_{2}} ; s\right)
\end{aligned}
$$

This contradicts with $\left(b_{g_{1}}, b_{g_{2}}\right)$ being optimal. Therefore, in equilibrium $b_{g_{1}}=b_{g_{2}}$.

The global's optimization problem can be expressed as: $\operatorname{Max}_{b} \Pi(b ; s)=\left(\frac{b}{100}\right)^{2} s+$ $2 \frac{b s}{100}-2 \int_{0}^{b} p \frac{d p}{100}$

It is easy to see that, when complementarities exist, the global's optimization problem has an interior solution for low signals and a corner solution at $b=100$ for high signals. The interior solution is a solution to the first order condition $\frac{\partial \Pi(b ; s)}{\partial b}=0$, or equivalently it solves $\frac{b s}{100}+s-b=0$. Hence, $b=\frac{100 s}{100-s}$ for $s<50$. When $s \geq 50$, the global is indifferent between 100 or anything more than 100. When the bidding space is restricted to the signal space, for example, the best response of the global with signal $s$ is

$b_{g}^{*}(s)=\min \left\{\frac{100 s}{100-s}, 100\right\}$. 